\title{
Distribution and ultrastructural localization of the glucagon-like peptide-1 receptor (GLP-1R) in the rat brain
}

\author{
Erzsébet Farkas ${ }^{1}$ - Anett Szilvásy-Szabó ${ }^{1} \cdot$ Yvette Ruska ${ }^{1} \cdot$ Richárd Sinkó $^{1} \cdot$ Morten Grønbech Rasch $^{2}$. \\ Thomas Egebjerg ${ }^{2}$. Charles Pyke ${ }^{2} \cdot$ Balázs Gereben $^{1} \cdot$ Lotte Bjerre Knudsen $^{2} \cdot$ Csaba Fekete $^{1,3}$
}

Received: 5 March 2020 / Accepted: 25 November 2020 / Published online: 20 December 2020

(C) The Author(s) 2020

\begin{abstract}
Glucagon-like peptide-1 (GLP-1) inhibits food intake and regulates glucose homeostasis. These actions are at least partly mediated by central GLP-1 receptor (GLP-1R). Little information is available, however, about the subcellular localization and the distribution of the GLP-1R protein in the rat brain. To determine the localization of GLP-1R protein in the rat brain, immunocytochemistry was performed at light and electron microscopic levels. The highest density of GLP-1R-immunoreactivity was observed in the circumventricular organs and regions in the vicinity of these areas like in the arcuate nucleus (ARC) and in the nucleus tractus solitarii (NTS). In addition, GLP-1R-immunreactive (IR) neuronal profiles were also observed in a number of telencephalic, diencephalic and brainstem areas and also in the cerebellum. Ultrastructural examination of GLP1R-immunoreactivity in energy homeostasis related regions showed that GLP-1R immunoreactivity is associated with the membrane of perikarya and dendrites but GLP-1R can also be observed inside and on the surface of axon varicosities and axon terminals. In conclusion, in this study we provide a detailed map of the GLP-1R-IR structures in the CNS. Furthermore, we demonstrate that in addition to the perikaryonal and dendritic distribution, GLP-1R is also present in axonal profiles suggesting a presynaptic action of GLP-1. The very high concentration of GLP-1R-profiles in the circumventricular organs and in the ARC and NTS suggests that peripheral GLP-1 may influence brain functions via these brain areas.
\end{abstract}

Keywords GLP-1 receptor · Axonal localization · Distribution · Immunohistochemistry · Electron microscopy

\section{Introduction}

Glucagon-like peptide-1 (GLP-1) is an incretin hormone (Baggio and Drucker 2007). It is derived from the posttranslational processing of proglucagon (Baggio and Drucker 2007). This prohormone is synthesized by three cell populations, the neuroendocrine L cells of the intestinal

Supplementary Information The online version contains supplementary material available at https://doi.org/10.1007/s0042 9-020-02189-1.

Csaba Fekete

csaba.fekete@koki.hu

1 Laboratory of Integrative Neuroendocrinology, Institute of Experimental Medicine, Budapest 1083, Hungary

2 Novo Nordisk A/S, 2760 Måløv, Denmark

3 Department of Medicine, Division of Endocrinology, Diabetes and Metabolism, Tupper Research Institute, Tufts Medical Center, Boston, MA 02111, USA mucosa, the $\beta$ cells of the pancreatic Langerhans islands and in a neuronal population located in the nucleus tractus solitarii (NTS) and intermediate reticular nucleus of the medulla oblongata (Muller et al. 2019). GLP-1 is produced primarily in the gut and the brain as its production requires $\mathrm{PC} 1 / 3$ catalyzed posttranslational processing of proglucagon (Muller et al. 2019). Stress and type 2 diabetes, however, upregulate $\mathrm{PC} 1 / 3$ expression in pancreatic $\alpha$ cells enabling GLP-1 production in this tissue (Chen et al. 2018). GLP-1 has a critical role in the regulation of energy and glucose homeostasis (Andersen et al. 2018), and exerts its effects via the GLP-1 receptor (GLP-1R). It decreases circulating glucose levels by slowing down the gastric emptying, and by stimulating insulin production and inhibiting glucagon secretion (Andersen et al. 2018). Furthermore, GLP-1 has a potent inhibitory effect on food intake and can decrease the hedonic value of food and the motivation to eat (Andersen et al. 2018; Hayes and Schmidt 2016). These properties have made GLP-1R an important drug target in the field of type 2 diabetes and obesity. Long-acting GLP-1R agonists, 
liraglutide, semaglutide and dulaglutide have been marketed for the treatment of type 2 diabetes and have been shown to also provide cardiovascular risk reduction (Gerstein et al. 2019; Marso et al. 2016; Davies et al. 2017), while liraglutide is approved for the treatment of obesity (Pi-Sunyer et al. 2015). Semaglutide has completed phase 3 for obesity. Studies using a variety of histology-based methods have convincingly demonstrated the widespread distribution of GLP-1R in the central nervous system (CNS) (Merchenthaler et al. 1999; Cork et al. 2015; Heppner et al. 2015; Jensen et al. 2018). Little information is available, however, about the distribution of the GLP-1R protein at the ultrastructural level in brain tissue. In addition, no previous description of GLP$1 \mathrm{R}$ immunoreactivity in the rat CNS has been published.

Due to the very short half-life, the ability of endogenous GLP-1 to enter the brain has been debated, but the clinically used, long-acting GLP-1R agonists (liraglutide and semaglutide) have been proven to enter the brain of rodents and in these animals, can bind to central neuronal groups relevant for the weight effects observed in the clinic (Secher et al. 2014; Gabery et al. 2020). Thus, it is important to understand which neuronal populations can be influenced by the administration of these compounds.

We, therefore, mapped the distribution of the GLP$1 \mathrm{R}$-immunoreactive (IR) profiles in the rat brain and examined the subcellular localization of this receptor in energy homeostasis related brain regions using immune-electron microscopy.

\section{Material and methods}

\section{Animals}

Adult, male Sprague-Dawley rats weighing $250-280 \mathrm{~g}$ and wild type C57/BL/6 and GLP-1R KO mice were used.

Animals were housed under standard environmental conditions (lights on between 06.00 and $18.00 \mathrm{~h}$, temperature $22 \pm 1{ }^{\circ} \mathrm{C}$, mouse chow and water ad libitum). All experimental protocols were reviewed and approved by the Animal Welfare Committee at the Institute of Experimental Medicine. All animal experiments were performed in accordance with relevant guidelines of Novo Nordisk.

Rats were anaesthetized with a mixture of ketamine and xylazine (ketamine $50 \mathrm{mg} / \mathrm{kg}$, xylazine $10 \mathrm{mg} / \mathrm{kg}$ body weight, i.p.) and were perfused transcardially with $30 \mathrm{ml}$ $0.01 \mathrm{M}$ phosphate-buffered saline $\mathrm{pH} 7.4$ (PBS), followed by $150 \mathrm{ml} 3 \%$ paraformaldehyde (Science Services $\mathrm{GmbH}$, München, Germany) plus 1\% acrolein (Merck KGaA, Darmstadt, Germany) in $0.1 \mathrm{M}$ phosphate buffer pH 7.4 (PB). Anaesthetized mice were perfused transcardially with $10 \mathrm{ml}$ $0.01 \mathrm{M}$ phosphate-buffered saline $\mathrm{pH} 7.4$ (PBS), followed by $40 \mathrm{ml}$ mixture of 3\% paraformaldehyde (Science Services
$\mathrm{GmbH}$, München, Germany) and 1\% acrolein (Merck KGaA, Darmstadt, Germany) in 0.1 M phosphate buffer $\mathrm{pH} 7.4$ (PB). The brains were rapidly removed. For light microscopy $(N=6$ rats; $N=3$ WT C57BL/6 mice; $N=2$ GLP-1R KO mice), the brains were cryoprotected in $30 \%$ sucrose in $0.01 \mathrm{M}$ PBS overnight at room temperature (RT). For electron microscopy ( $N=3$ rats; $N=3 \mathrm{C} 57 \mathrm{BL} / 6$ mice), the brains were postfixed in $4 \%$ PFA in $0.1 \mathrm{M} \mathrm{PB} \mathrm{pH} \mathrm{7.4.}$

\section{Antibodies}

The light and electron microscopic studies on rat tissues were performed using the mouse monoclonal anti-GLP-1R antibody (Clone 7F38A2; $0.5 \mu \mathrm{g} / \mathrm{ml}$, Novo Nordisk A/S) (Jensen et al. 2018). To determine the specificity of the antibody, immunocytochemistry was performed on brain sections of WT and GLP-1R knockout mice using the same protocol as the one used for rat sections. Endogenous IgGs are abundant in the circumventricular organs and in the arcuate nucleus of the mouse brain (Fabian and Ritchie 1986) and therefore, immunostaining using mouse primary antibody results in non-specific labeling in these regions due to the reaction of endogenous $\mathrm{IgG}$ with the secondary antibody. To validate the specificity of the monoclonal anti-GLP$1 \mathrm{R}$ antibody in these brain regions, a rabbitized version of the antibody was generated using recombinant technology, whereby the heavy and light chain variable regions from the mouse monoclonal anti-GLP-1R antibody were grafted onto a rabbit IgG to generate a rabbit monoclonal version of clone 7F38A2 (detailed in Supplemental Fig. 1 and as described earlier (Bhatti et al. 2019)).

\section{Single-labeling immunocytochemistry for detection of GLP-1R-immunoreactivity}

Serial, $25 \mu \mathrm{m}$ thick coronal sections through the whole brain were cut on a freezing microtome (Leica Microsystems, Vienna, Austria). The sections were washed with PBS and treated with $1 \%$ sodium borohydride (Cat. \#45882, Merck) in $0.1 \mathrm{M}$ PB for $30 \mathrm{~min}$ and then treated with $0.5 \%$ Triton X-100 (Cat. \# T9284, Merck) and 0.5\% $\mathrm{H}_{2} \mathrm{O}_{2}$ (Cat. \# 95321, Merck) in $0.01 \mathrm{M}$ PBS for $15 \mathrm{~min}$. Nonspecific antibody binding was blocked with treatment in $2 \%$ normal horse serum (NHS) in PBS for 20 min, and then the rat sections were placed in mouse monoclonal anti-GLP-1R antibody (Clone 7F38A2; $0.5 \mu \mathrm{g} / \mathrm{ml}$, Novo Nordisk A/S) while the mouse sections were immersed in either mouse monoclonal anti-GLP-1R antibody (Clone 7F38A2; $0.5 \mu \mathrm{g} / \mathrm{ml}$ ) or in rabbitized monoclonal antibody against GLP-1R $(0.016 \mu \mathrm{g} /$ $\mathrm{ml}$ ) diluted in serum diluent ( $2 \% \mathrm{NHS}+0.2 \%$ sodium azide in PBS) for 2 days at $4{ }^{\circ} \mathrm{C}$. After rinsing in PBS, the sections were incubated in either biotinylated donkey antimouse IgG (Cat. \# 715-065-151, Jackson ImmunoResearch 
Europe Ltd, Ely, UK) or biotinylated donkey anti-rabbit IgG (Cat. \# 711-065-152, Jackson ImmunoResearch Europe Ltd, Ely, UK) diluted at 1:500 in serum diluent at room temperature. After washing in PBS, the sections were treated with avidin-biotin-peroxidase complex (ABC Elite, Cat. \# PK-6100, 1:1000, Vector Laboratories Ltd, Peterborough, UK) for an hour and the GLP-1R-immunoreactivity was developed in Ni-DAB developer $(0.05 \%$ diaminobenzidine and $0.15 \%$ nickel ammonium sulfate $0.005 \% \mathrm{H}_{2} \mathrm{O}_{2}$ in $0.05 \mathrm{M}$ Tris buffer, $\mathrm{pH}$ 7.6). The sections were mounted onto glass slides and coverslipped with DPX mounting medium (Cat. \# 06522, Merck). Images were taken using a Zeiss AxioImager M1 microscope equipped with AxioCam MRc5 digital camera (Carl Zeiss Inc., Darmstadt, Germany). To facilitate the mapping of GLP-1R-IR structures, mosaic images were taken. The maps were drawn in CorelDraw Graphics Suite (Corel Corporation, Ottawa, Canada) based on these images and the plates of the Atlas of Paxinos and Watson (Paxinos and Watson 2013). One set of native sections from each brain was Nissl stained to facilitate the mapping. Every fourth section of three rat brains were analyzed by two independent observers.

\section{Tissue preparation for ultrastructural studies}

Serial, $25 \mu \mathrm{m}$ thick coronal sections were cut on a Leica VT 1000 S vibratome (Leica Microsystems, Vienna, Austria) through the whole brains. The sections were collected in 0.1 M PBS ( $\mathrm{pH} 7.4$ ). The sections were transferred into anti-freeze solution (30\% ethylene glycol (Cat. \# 297, VWR Chemicals); $25 \%$ glycerol (Cat. \# 24388.295, VWR Chemicals); $0.05 \mathrm{M} \mathrm{PB}$ ) and stored at $-20{ }^{\circ} \mathrm{C}$ until their use for immunohistochemistry.

The sections were then washed with PBS and treated with $1 \%$ sodium borohydride in $0.1 \mathrm{M}$ PB for $30 \mathrm{~min}$ and then with $0.5 \% \mathrm{H}_{2} \mathrm{O}_{2}$ in PBS for $15 \mathrm{~min}$. The sections were cryoprotected in $15 \%$ sucrose in PBS for $30 \mathrm{~min}$ at room temperature and in $30 \%$ sucrose in PBS overnight at $4{ }^{\circ} \mathrm{C}$, and then quickly frozen over liquid nitrogen and thawed. The freezing-thawing cycle was repeated three times to improve antibody penetration.

The pretreated sections were incubated in $2 \%$ normal horse serum (NHS, diluted in $0.1 \mathrm{M}$ PBS) for $20 \mathrm{~min}$. Then, the rat sections were placed in mouse monoclonal anti-GLP$1 \mathrm{R}(0.5 \mu \mathrm{g} / \mathrm{ml}$, clone 7F38A2) and the mouse sections were placed in rabbitized monoclonal antibody against GLP-1R $(0.016 \mu \mathrm{g} / \mathrm{ml})$ in serum diluent for 4 days at $4{ }^{\circ} \mathrm{C}$. After rinsing in PBS, the sections were incubated in biotinylated donkey anti-mouse or anti-rabbit IgG diluted at 1:500 in serum diluent overnight at $4{ }^{\circ} \mathrm{C}$ followed by treatment in ABC (1:1000). The GLP-1R-immunoreactivity was developed in Ni-DAB developer. The sections were rinsed in $0.2 \mathrm{M}$ sodium citrate (Cat. \# S4641, Merck) pH 7.5, and then the immunoreaction was silver intensified with the Gallyas method (Liposits et al. 1984) for $2.5 \mathrm{~min}$. The sections were placed in 0.05\% gold-chloride (Cat. \# 520918, Merck) for $10 \mathrm{~min}$ at room temperature, washed in $0.2 \mathrm{M}$ sodium citrate, $\mathrm{pH} 7.5$, and in $3 \%$ sodium-thiosulphate solution for $10 \mathrm{~min}$ each at room temperature.

\section{Embedding and ultrastructural examination of the immunostained sections}

Sections were incubated in $1 \%$ osmium-tetroxide for $1 \mathrm{~h}$ at room temperature and then treated with $2 \%$ uranyl acetate in $70 \%$ ethanol for $30 \mathrm{~min}$. Following dehydration in an ascending series of ethanol and acetonitrile (Cat. \# 360457, Merck), the sections were flat embedded in Durcupan ACM epoxy resin (Cat. \# 44610, Merck) on liquid release agent (Cat. \# 70880, Electron Microscopy Sciences)-coated slides, and polymerized at $56{ }^{\circ} \mathrm{C}$ for 2 days. After polymerization, 60-70 nm thick ultrathin sections were cut with Leica UCT ultramicrotome (Leica Microsystems). The ultrathin sections were mounted onto Formvar-coated, single-slot grids, treated with lead citrate and examined with a JEOL-100 C transmission electron microscope.

\section{Results}

\section{Antibody validation}

To determine the specificity of the mouse monoclonal antiGLP-1R antibody used throughout for mapping GLP-1R in rat brain sections, immunostaining was performed on brain sections of wild type and GLP-1R KO mice. The pattern of immunoreaction was very similar in WT mice (Fig. 1a, c, e, g) as it was observed in rats (Figs. 3, 4, 5, 6, 7 and 8) except in the circumventricular organs and most parts of the arcuate nucleus, which regions were almost completely filled with immunoreaction product in mice. In GLP-1R KO mice, the immunoreaction product was completely absent except in the circumventricular organs and most parts of the arcuate nucleus (Fig. 1b, d, f, h). It is well known that mouse IgG is present in these brain areas that is detected by the used secondary antibody (Fabian and Ritchie 1986). To be able to determine the specificity of the used antibody even in these brain regions, immunostaining was also performed using the rabbitized version of the monoclonal GLP-1R antibody that has identical antigen recognition region as the original mouse monoclonal antibody.

This immunostaining with the rabbitized antibody resulted in a very similar pattern as with the original mouse monoclonal antibody. However, in the circumventricular organs and in the ARC, the almost homogenous NiDAB precipitate was replaced with the labeling of neuronal profiles 


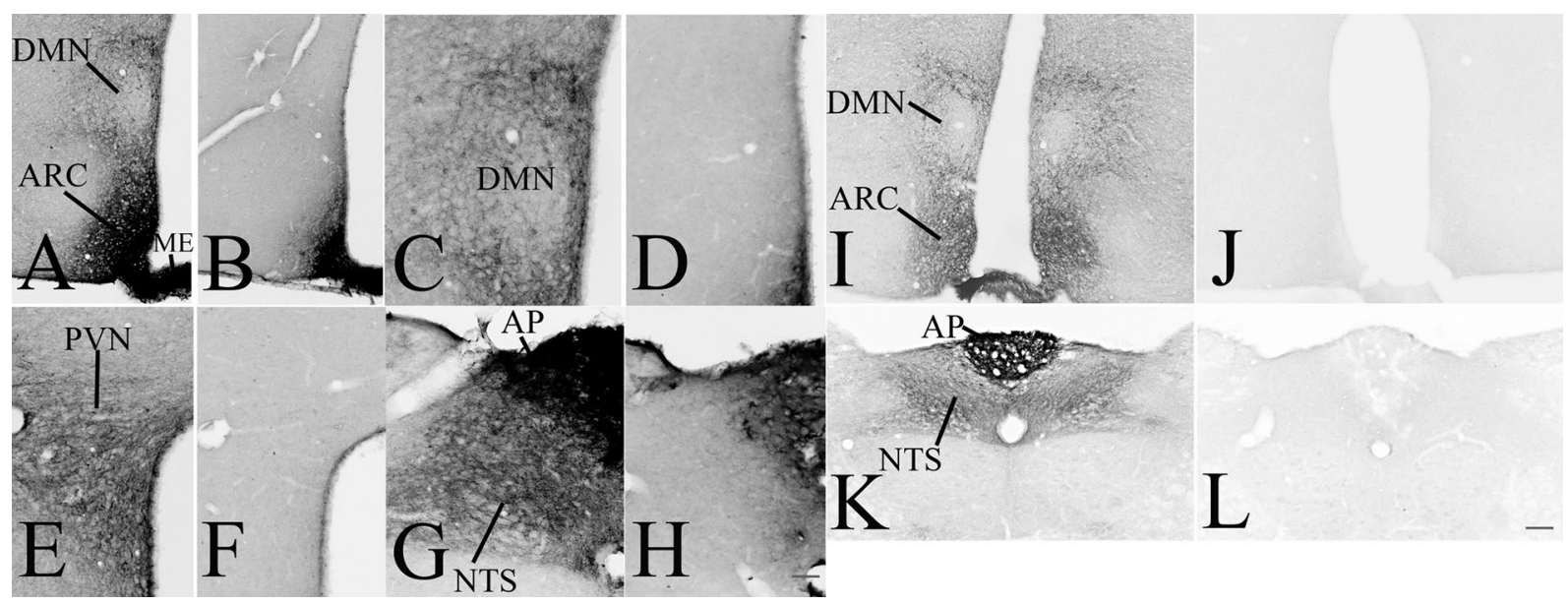

Fig. 1 Specificity of the used monoclonal GLP-1R antibody. GLP$1 \mathrm{R}$-immunoreactivity using the mouse monoclonal anti-GLP-1R IgG $(\mathbf{a}, \mathbf{c}, \mathbf{e}, \mathbf{f})$, results in similar immunostaining as it was observed in rats, however, the circumventricular organs, like the median eminence (ME) and the area postrema (AP) and parts of the arcuate nucleus (ARC), where mouse IgGs are present (Fabian and Ritchie 1986), are filled with immunoreaction product. In GLP-1R KO mice, the immunoreaction product is absent except the circumventricular organs and the ARC, where the used secondary antibody stains the

as it was observed in rats. The immunoreaction with this antibody was completely absent in all brain regions of GLP$1 \mathrm{R} \mathrm{KO}$ mice demonstrating the specificity of the antibody (Fig. 1k, l).

\section{Distribution of GLP-1R-immunoreactivity in the rat brain}

A widespread distribution of the GLP-1R protein was observed throughout the rostro-caudal extent of the brain. The GLP-1R-immunoreactivity had a similar distribution in the three studied brains. In general, the intensity of the GLP$1 \mathrm{R}$ immunoreactivity was the highest in the circumventricular organs including the area postrema, subfornical organ, median eminence and organum vasculosum laminae terminalis (OVLT), and in areas located in the close proximity of the circumventricular organs like the arcuate nucleus (ARC) and the NTS. GLP-1R immunoreactivity was observed in both fibers and cell bodies (Fig. 2). The distribution of GLP1R-IR fibers and cell bodies is summarized in Tables 1, 2, 3, 4, 5 and 6 and Fig. 3.

\section{Distribution of GLP-1R-immunoreactivity in the telencephalon}

High or moderate density of GLP-1R-IR elements were detected in the dorsal tenia tecta (fibers), olfactory tubercle (fibers and perikarya) (Figs. 3a and 4), lateral septal nuclei (Fibers and some perikarya), lateral stripe of the striatum mouse IgGs $(\mathbf{b}, \mathbf{d}, \mathbf{f}, \mathbf{h})$. To prove the specificity of the antibody even in these areas, immunostaining was performed in WT (i, k) and GLP$1 \mathrm{R} \mathrm{KO}(\mathbf{j}, \mathbf{l})$ mice using the rabbitized version of the antibody. The immunostaining with the rabbitized antibody in WT mice was highly similar than what was observed in rats, but the immunoreaction product was completely absent when sections of GLP-1R KO mice were stained. Scale bar (shown in $\mathbf{h}$ ): $\mathbf{c}-\mathbf{h}, 50 \mu \mathrm{m}$; (shown in $\mathbf{L}$ ) $\mathbf{a}, \mathbf{b}, \mathbf{i}-\mathbf{l}$ $100 \mu \mathrm{m} . D M N$ hypothalamic dorsomedial nucleus, $P V N$ hypothalamic paraventricular nucleus, NTS nucleus tractus solitarii

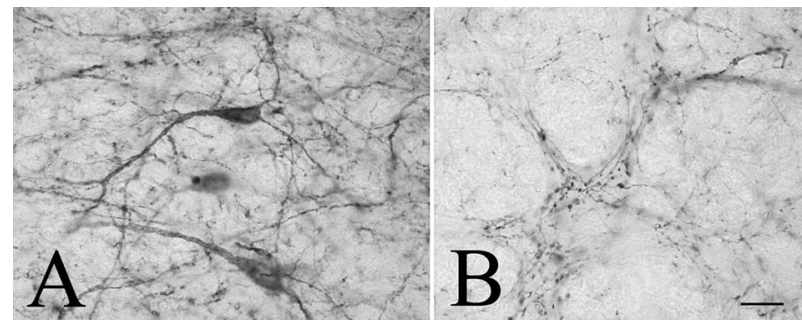

Fig. 2 Presence of the GLP-1R-immunoreactivity in both neuronal perikarya and axon like profiles. GLP-1R-immunoreactivity was frequently observed in the brain in neuronal perikarya and dendrites (a), but also in varicose axon like profiles (b). Scale bar $=20 \mu \mathrm{m}$

(fibers) (Figs. 3b-e and 4) and bed nucleus of the stria terminalis (fibers and perikarya) (Figs. 3d, g and 4). In the basal ganglia, low to moderate density of GLP-1R-IR fibers and cell bodies were detected in the nucleus accumbens shell, caudate putamen (Fig. 3a-g), globus pallidum (Fig. 3f, h, i) and ventral pallidum (Fig. 3b-f). High number of GLP-1R-IR cell bodies and fibers were observed in parts of the amygdala including the medial and central amygdaloid nucleus and sublenticular extended amygdala (Figs. 3h-j and Fig. 4). Within the amygdala, somewhat lower density of GLP-1R-IR elements was observed in the anterior part of the basomedial amygdala and in the intercalated amygdaloid nucleus. 
Table 1 Distribution of the GLP-1R-IR structures in the telencephalon

\begin{tabular}{llll}
\hline Brain areas & Processes & Somata & Abbreviation \\
\hline Dorsal tenia tecta & ++ & & DTT \\
Olfactory tubercle & ++ & $*$ & Tu \\
Lateral stripe of striatum & + & & LSS \\
Lateral septal nucleus intermediate part & +++ & $*$ & LSI \\
Lateral septal nucleus dorsal part & ++ & $*$ & LSD \\
Lateral septal nucleus ventral part & ++++ & $*$ & LSV \\
Nucleus accumbens schell & + & & AcbSH \\
Ventral Pallidum & ++ & $*$ & VP \\
Globus pallidum & ++ & $*$ & GP \\
Caudate Putamen & + & $*$ & CPu \\
Bed nucleus of the stria terminalis & ++ & $* *$ & BNST \\
Subfornical organ & +++ & & SFO \\
Interstitial nucleus of the posterior limb of the anterior & + & & IPAC \\
commissurae & & $* *$ & CeM \\
Central amygdaloid nucleus medial division & ++ & $*$ & BSTIA \\
Bed nucleus of the stria terminalis, & + & $*$ & SLEAM \\
intraamygdaloid division & + & $*$ & SLEAC \\
Sublenticular extended amygdala medial part & ++ & $*$ & MeAD \\
Sublenticular extended amygdala central part & ++ & $*$ & MeAV \\
Medial amygdaloid nucleus anterior dorsal part & ++ & $*$ & BMA \\
Medial amygdaloid nucleus anteroventral part & + & $*$ & I \\
Medial amygdaloid nucleus posterior part & ++ & + & \\
Basomedial amygdaloid nucleus anterior part & + & $*$ & \\
Intercalated nucleus of the amygdala & + & $*$ & \\
Intercalated amygdaloid nucleus main part & + & & \\
\hline
\end{tabular}

The GLP-1R-immunoreactive areas were ranked into four categories based on the density of immunoreactive fibers from "+", meaning low level to " ++++ " meaning "very high" level, and based on the density of immunoreactive perikarya from *meaning low to ***meaning high level
Very low level of immunoreactivity was observed in scattered perikarya in cortical areas and in the granular layer of the dentate gyrus. In these two areas, the density and the pattern of immunoreaction were highly variable among the studied brains.

\section{Distribution of the GLP-1R-immunoreactivity in the diencephalon}

A large number of thalamic nuclei also contained a dense network of GLP-1R positive fibers (Fig. 5), but the level of immunoreactivity was lower than in the previously described brain regions nuclei (Fig. 3h-k). GLP-1R-IR cell bodies were observed in the paratenial, parafascicular and ethmoid thalamic nuclei. The GLP-1R-IR fibers had more widespread distribution in the thalamus. Dense networks of GLP-1R fibers were observed in the interanterodorsal, paraventricular, paratenial and reuniens thalamic nuclei and in the ventral lateral geniculate nucleus. Less dense fiber networks were observed in the mediodorsal, anteromedial, anteroventral, lateroposterior, laterodorsal, central medial, centrolateral, parafascicular, posterior limitans and reticular thalamic nuclei (Fig. 3h-k).

In the epithalamus and subthalamus, a dense network of GLP-1R-IR fibers were detected in the zona incerta and the lateral habenular nucleus, while sparser fiber networks were observed in the subincertal, subthalamic and subgeniculate nuclei (Fig. 3i-k). In addition to fibers, the zona incerta also contained GLP-1R-IR cell bodies (Fig. 3i, j).

GLP-1R-IR cell bodies and fibers also had widespread distribution in the hypothalamus (Fig. 6). The density of the GLP-1R protein-containing profiles was the highest in the ARC, the hypothalamic paraventricular nucleus (PVN) (Fig. 3g-i), supraoptic nucleus, hypothalamic dorsomedial nucleus (DMN) and in the median eminence (ME) (Fig. 3f-i). Dense GLP-1R-immunoreactivity was also observed in the medial and lateral mammillary nuclei and in the supramammillary nucleus (Fig. 3k). Moderate density signal was detected in the preoptic and the lateral hypothalamic areas. In contrast to the surrounding areas and nuclei, lack of GLP-1R protein was observed in the ventromedial hypothalamic nucleus (Fig. 3i, j). 
Table 2 Distribution of the GLP-1R-IR structures in the thalamus, subthalamus and epithalamus

\begin{tabular}{llll}
\hline Brain areas & Processes & Somata & Abbreviation \\
\hline Mediodorsal thalamic nucleus lateral part & + & MDL \\
Interanterodorsal thalamic nucleus & +++ & IAD \\
Anteromedial thalamic nucleus & + & AM \\
Anteroventral thalamic nucleus medial part & + & AVDM \\
Lateroposterior thalamic nucleus mediorostral part & + & LPMR \\
Laterodorsal thalamic nucleus ventrolateral part & + & LDVL \\
Central medial thalamic nucleus & + & CM \\
Centrolateral thalamic nucleus & + & CL \\
Parafascicular thalamic nucleus & + & PF \\
Paraventricular thalamic nucleus & ++ & PV \\
Paratenial thalamic nucleus & ++ & PT \\
Reuniens thalamic nucleus & ++ & Re \\
Posterior limitans thalamic nucleus & + & PLi \\
Medial geniculate nucleus medial part & + & MGM \\
Ventral lateral geniculate nucleus & ++ & VLG \\
Ethmoid thalamic nucleus & + & Eth \\
Scaphoid thalamic nucleus & + & Sc \\
Reticular thalamic nucleus & + & Rt \\
Lateral Habenular nucleus & + * & & LHb \\
Subincertal nucleus & + & Sub1 \\
Subthalamic nucleus & ++ & STh \\
Subgeniculate nucleus & + & SubG \\
Suprageniculate thalamic nucleus & + & SG \\
Zona incerta & + & ZI \\
\hline & + & & \\
\hline
\end{tabular}

The GLP-1R-immunoreactive areas were ranked into four categories based on the density of immunoreactive fibers from "+", meaning low level to " ++++ " meaning "very high" level, and based on the density of immunoreactive perikarya from *meaning low to ***meaning high level

\section{Distribution of GLP-1R in the brainstem}

The most widespread distribution of the GLP-1R-IR profiles was observed in the brainstem (Figs. 31-p and 7). The reticular formation including the nuclei of cranial nerves contained GLP-1R-IR fibers and perikarya along the entire brainstem (Fig. 31-p). The periaqueductal gray also contained low to moderate levels of GLP-1R-IR fibers. Some parts of the periaqueductal gray including the lateral periaqueductal area also contained GLP-1R-IR perikarya. Within the mesencephalon, the highest density of GLP-1R-immunoreactivity was observed in the lateral subnucleus of the interpeduncular nucleus (Fig. 3m). GLP1R-IR fibers were detected in all parts of the dorsal raphe nucleus, but GLP-1R-IR perikarya were observed only in the dorsal part of this nucleus (Fig. 3m). In the substantia nigra, GLP-1R-IR fibers were found only in the medial tier of the compact part, while immunoreactive perikarya were observed in the reticular part of the nucleus (Fig. 31). In the tectum, low level of GLP-1R-immunoreactivity was only observed in the optic nerve layer and intermediate white layer of the superior colliculus (Fig. 31, $\mathrm{m})$. In the pons, the highest density of GLP-1R-IR fibers was detected in the external part of the lateral parabrachial nucleus (LPBE) (Fig. 3n). The other parts of the parabrachial nucleus also contained GLP-1R-IR fibers, but in lower density than the LPBE. The dorsal tegmental nucleus the laterodorsal tegmental nucleus, the $\beta$ part of the central gray, the raphe magnus and the caudal part of the dorsal raphe nucleus also contained high density of GLP-1R-IR fibers (Fig. 3n, o). Especially high density of GLP-1R-IR perikarya were detected in the central part of the dorsal tegmental nucleus, but GLP-1R-IR perikarya were also detected in the caudal part of the dorsal raphe nucleus, dorsomedial tegmental area, ventral part of the subceroleus nucleus, the ventrolateral part of the principal sensory trigeminal nucleus (Fig. 3n).

The highest level of GLP-1R-immunoreactivity was observed in the medulla, in the area postrema where numerous perikarya were observed in a very dense network of fibers (Fig. 3p). In the close proximity of the area postrema, the high density of GLP-1R-IR fibers was observed in the NTS. In addition, a dense fiber network was observed in the raphe pallidus and in the nuclei of the inferior olive. 
Table 3 Distribution of the GLP-1R-IR structures in the hypothalamus

\begin{tabular}{|c|c|c|c|}
\hline Brain areas & Processes & Somata & Abbreviation \\
\hline Organum vasculosum laminae terminalis & +++ & & VOLT \\
\hline Medial preoptic area & ++ & $*$ & MPA \\
\hline Medial preoptic nucleus & ++ & & MPOC \\
\hline Lateral preoptic area & + & & LPO \\
\hline Ventromedial preoptic nucleus & ++ & & VMPO \\
\hline Median preoptic nucleus & +++ & & $\mathrm{MnPO}$ \\
\hline Anteroventral periventric nucleus & ++ & & AVPe \\
\hline Supraoptic nucleus & +++ & & SO \\
\hline Paraventricular nucleus anterior parvocellular subdivision & ++ & $*$ & PaAP \\
\hline Paraventricular nucleus magnocellular division & +++ & $*$ & PaMM \\
\hline Paraventricular nucleus medial parvocellular subdivison & +++ & * & PaMP \\
\hline Paraventricular nucleus ventral parvocellular subdivison & +++ & $* *$ & $\mathrm{PaV}$ \\
\hline Paraventricular nucleus posterior part & ++ & & $\mathrm{PaPo}$ \\
\hline Dorsomedial hypothalamic nucleus compact part & ++ & & DMC \\
\hline Dorsomedial hypothalamic nucleus dorsal part & +++ & & DMD \\
\hline Dorsomedial hypothalamic nucleus ventral part & +++ & $*$ & DMV \\
\hline Anterior hypothalamic area central & ++ & & $\mathrm{AHC}$ \\
\hline Periventricular hypothalamic nucleus & +++ & $*$ & $\mathrm{Pe}$ \\
\hline Arcuate nucleus & ++++ & $* * *$ & ARC \\
\hline Dorsal hypothalamic area & ++ & & DA \\
\hline Lateral hypothalamus & ++ & $*$ & LH \\
\hline Perifornical part of lateral hypothalamus & ++ & & PeFLH \\
\hline Peduncular part of lateral hypothalamus & + & & PLH \\
\hline Posterior hypothalamic area & ++ & $*$ & PHA \\
\hline Posterior hypothalamic area dorsal & ++ & & PHD \\
\hline Medial forebrain bundle & + & & $\mathrm{mfb}$ \\
\hline Median eminence & ++++ & & $\mathrm{Me}$ \\
\hline Terete hypothalamic nucleus & + & & $\mathrm{Te}$ \\
\hline Tuberal region of lateral hypothalamus & + & $*$ & TuLH \\
\hline Supramammillary nucleus medial & +++ & & SuMM \\
\hline Medial tuberal nucleus & + & & MTu \\
\hline Medial mammillary nucleus & +++ & & $\mathrm{MnM}$ \\
\hline Lateral mammillary nucleus & +++ & & LM \\
\hline
\end{tabular}

The GLP-1R-immunoreactive areas were ranked into four categories based on the density of immunoreactive fibers from "+", meaning low level to " ++++ " meaning "very high" level, and based on the density of immunoreactive perikarya from *meaning low to ***meaning high level

\section{Cerebellum}

In the cerebellum, dense GLP-1R-immunoreactivity with punctuate appearance filled the cell bodies of the Purkinje cells and the entire molecular layer (Fig. 8). Very low levels of punctuate GLP-1R-immunoreactivity was observed in the granular layer.

\section{Ultrastructural localization of the GLP-1R-immunoreactivity}

To understand the subcellular localization of GLP-1R protein, the ultrastructural examination of GLP-1R-immunoreactivity was performed in the circumventricular organs and the surrounding areas, where the density of the GLP-1R-immunoreactivity was highest, including the ARC (Fig. 9), ME (Fig. 10), AP (Fig. 11) and NTS (Fig. 12). The silver particles labeling the GLP-1R-immunoreactivity were often detected along the membrane of perikarya, dendrites and axons. In the ARC, GLP-1R-immunoreactivity was present in the membrane of the axons (Fig. 9a), dendrites (Fig. 9b-d) and cell bodies (Fig. 9d). In axons, GLP-1R-immunoreactivity was also associated with small, clear, as well as dense core vesicles suggesting that GLP-1R is transported in these vesicles. GLP$1 \mathrm{R}$-immunoreactivity was also associated with axons in 
Table 4 Distribution of the GLP-1R-IR structures in the mesencephalon

\begin{tabular}{|c|c|c|c|}
\hline Brain areas & Processes & Somata & Abbreviation \\
\hline Anterior pretectal nucleus & ++ & $*$ & APT \\
\hline Interpeduncular nucleus lateral part & +++ & $*$ & IPL \\
\hline Substancia Nigra compact part, medial tier & + & & SNCM \\
\hline Substancia Nigra reticular part & & $*$ & SNR \\
\hline Medial lemniscus & + & & $\mathrm{ml}$ \\
\hline Trigeminothalamic tract & + & & tth \\
\hline Parabrachial pigmented nucleus & $+/++$ & & PBP \\
\hline Parainterfascicular nucleus & + & & PIF \\
\hline Paranigral nucleus of VTA & + & & PN \\
\hline Ventral tegmental area & + & & VTA \\
\hline Interfascicular nucleus & + & & $\mathrm{IF}$ \\
\hline Caudal linear nucleus of the raphe & + & & CLi \\
\hline Retrorubral nucleus & + & & RR \\
\hline Retrorubral field & + & & RRF \\
\hline Pararubral nucleus & ++ & $*$ & $\mathrm{PaR}$ \\
\hline Red nucleus parvicellular part & + & & $\mathrm{RPC}$ \\
\hline Red nucleus magnocellular part & + & $*$ & $\mathrm{RMC}$ \\
\hline Oculomotor nucleus & + & & $3 \mathrm{~N}$ \\
\hline Oculomotor nucleus parvicellular part & + & & 3PC \\
\hline Supraoculomotor periaquaduct & + & & SU3 \\
\hline Supraoculomotor cap & + & & SU3C \\
\hline Trochlear nucleus & + & & $4 \mathrm{~N}$ \\
\hline Edinger-Westphal nucleus & ++ & & EW \\
\hline Periaqueductal gray dorsolateral part & + & $*$ & DLPAG \\
\hline Lateral periaqueductal gray & ++ & $*$ & LPAG \\
\hline Dorsomedial Periaqueductal gray & $+/++$ & & DMPAG \\
\hline Ventrolateral Periaqueductal gray & ++ & $* *$ & VLPAG \\
\hline Precuneiform nucleus & + & & $\mathrm{PrCnF}$ \\
\hline Mesencephalic reticular formation & + & & $\mathrm{mRT}$ \\
\hline Isthmic reticular formation & + & * & isRT \\
\hline Microcellular tegmental nucleus & + & & MiTg \\
\hline Dorsal raphe nucleus lateral part & ++ & $* *$ & DRL \\
\hline Dorsal raphe nucleus dorsal part & ++ & $* *$ & DRD \\
\hline Posterodorsal raphe nucleus & + & & PDR \\
\hline Dorsal raphe nucleus ventral part & + & & DRV \\
\hline Optic nerve layer of superior colliculus & + & * & Op \\
\hline Intermediate white layer of superior colliculus & + & & InWh \\
\hline
\end{tabular}

The GLP-1R-immunoreactive areas were ranked into four categories based on the density of immunoreactive fibers from "+", meaning low level to " ++++ " meaning "very high" level, and based on the density of immunoreactive perikarya from *meaning low to ***meaning high level the mouse ARC demonstrating that the axonal localization of the receptor is not a species-specific feature (Fig. 9e).

In the external zone of the ME, where the hypophysiotropic axons terminate, GLP-1R-immunoreactivity was associated with the outer surface of numerous axon terminals (Fig. 10a, b). GLP-1R-immunoreactivity was, however, also present in small clear vesicles (Fig. 10a) and in dense-core vesicles (Fig. 10b) of these axons. The density of the GLP-1R-IR hypophysiotropic axon terminals was very high close to the portal capillaries in the external zone (Fig. 10a). GLP-1R-immunoreactivity was not detected in the tanycytes of the ME.

In the AP, silver-gold granules labeling GLP-1R were primarily present on the outer surface of the membrane of axons, dendrites and cell bodies (Fig. 11a-c). In most cases, the GLP-1R-immunoreactivity completely surrounded these profiles. 
Table 5 Distribution of the GLP-1R-IR structures in the pons

\begin{tabular}{|c|c|c|c|}
\hline Brain areas & Processes & Somata & Abbreviation \\
\hline Reticulotegmental nucleus pons & + & & RtTg \\
\hline Locus ceroleus & + & & $\mathrm{LC}$ \\
\hline Subcoerulens nucleus alpha part & + & & SubCA \\
\hline Subcoerulens nucleus dorsal part & + & & SubCD \\
\hline Subcoerulens nucleus ventral part & ++ & $* *$ & SubCV \\
\hline Pedunculopontine tegmental nucleus & + & & PTg \\
\hline Pontine reticular nucleus oral part & $+/++$ & $*$ & $\mathrm{PnO}$ \\
\hline Pontine reticular nucleus caudal part & ++ & * & $\mathrm{PNC}$ \\
\hline Intermediate reticular nucleus alpha & + & $*$ & IRtA \\
\hline Laterodorsal tegmental nucleus & ++ & * & LDTg \\
\hline Dorsal tegmental nucleus central part & ++ & $* * *$ & DTgC \\
\hline Dorsal tegmental nucleus pericentral part & ++ & & DTgP \\
\hline Dorsomedial tegmental area & + & $*$ & DMTg \\
\hline Medial longitudional fascicle & + & & mlf \\
\hline Central gray $ß$ part & ++ & & CGB \\
\hline Parabrachial nucleus & + & & PB \\
\hline Lateral parabrachial nucleus external part & +++ & & LPBE \\
\hline Motor trigeminal nucleus & ++ & & Mo5 \\
\hline Principal sensory trigeminal nucleus ventrolateral part & + & $*$ & Pr5VL \\
\hline Peritrigeminal zone & ++ & & P5 \\
\hline Spinal trigeminal nucleus & $+/++$ & * & Sp5 \\
\hline Spinal trigeminus nucleus dorsomedial part & ++ & & DMSp5 \\
\hline Trigeminal-solitary transition zone & ++ & * & 5Sol \\
\hline Facial nucleus & + & & 7 \\
\hline Lateral paragigantocellular nucleus & ++ & * & LPGi \\
\hline Raphe magnus & ++ & * & $\mathrm{RMg}$ \\
\hline Lateroventral periolivary nucleus & + & & LVPO \\
\hline Medial lemniscus & + & & $\mathrm{ml}$ \\
\hline Dorsal raphe nucleus caudal part & ++ & * & DRC \\
\hline
\end{tabular}

The GLP-1R-immunoreactive areas were ranked into four categories based on the density of immunoreactive fibers from "+", meaning low level to "++++" meaning "very high" level, and based on the density of immunoreactive perikarya from *meaning low to ***meaning high level
In the NTS, GLP-1R-immunoreactivity was present in axons (Fig. 12a) and dendrites (Fig. 12b). In the axons, the GLP-1R-immunoreactivity was primarily localized to small clear vesicles. In some cases, the labeled vesicles associated with microtubules of dendrites. In addition, we observed GLP-1R-immunoreactivity in the membranes of labeled processes, but compared to the previously described brain regions, the density of GLP-1R-immunoreactivity was lower in the membranes of axons and dendrites (Fig. 12a, b).

\section{Discussion}

In the current manuscript, we provide a detailed map of the GLP-1R-immunoreactive profiles in the rat brain and describe the subcellular localization of this receptor. In addition to the expected perikaryonal and dendritic localization of the GLP-1R, numerous varicose, axonlike GLP-1R-IR profiles were observed in many parts of the brain. Using immuno-electron microscopy, we demonstrated that indeed, GLP-1R-immunoreactivity was associated not only to perikarya and dendrites but also to axons. GLP-1R was observed in axon terminals forming both symmetric and asymmetric type synapses.

Using peripheral administration of superresolution microscopy compatible GLP-1R antagonist, Ast et al. (2020) also observed ligand binding around the cells of the ARC and AP. However, at the resolutions used, they were unable to distinguish axonal staining. Using electron microscopy to visualize cell membranes, we now provide further information showing that in addition to perikarya and dendrites, the GLP-1R is also present in association to the membranes of axons in these brain regions. 
Table 6 Distribution of the GLP-1R-IR structures in the medulla oblongata

\begin{tabular}{|c|c|c|c|}
\hline Brain areas & Processes & Somata & Abbreviation \\
\hline Intermediate reticular nucleus & ++ & $*$ & IRt \\
\hline Intermediate reticular nucleus alpha & + & * & IRtA \\
\hline Gigatocellular reticular nucleus & + & * & $\mathrm{Gi}$ \\
\hline Gigatocellular reticular nucleus alpha & ++ & & GiA \\
\hline Lateral paragigatocellular nucleus & + & & LPGiA \\
\hline Lateral reticular nucleus & + & $*$ & LRt \\
\hline Lateral reticular nucleus substrigeminal part & ++ & * & LRtS5 \\
\hline Dorsal paragigatocellular nucleus & ++ & * & DPGi \\
\hline Parapyramidal nucleus of raphe & ++ & & PPy \\
\hline Parvicellular reticular nucleus & ++ & $*$ & PCRt \\
\hline Spinal trigeminal nucleus & + & $*$ & Sp5 \\
\hline Trigeminal-solitary transition zone & ++ & $*$ & 5 Sol \\
\hline Nucleus of the solitary tract & +++ & & NTS \\
\hline Area postrema & ++++ & $* * * *$ & AP \\
\hline Dorsal motor nucleus of vagus & +++ & & $10 \mathrm{~N}$ \\
\hline Hypoglossal nucleus & + & & $12 \mathrm{~N}$ \\
\hline Ad1 adrenergic and NA1 noradrenergic region & + & & Ad1/NA1 \\
\hline Ambigus nucleus & + & & Amb \\
\hline Rostral Ventral Respiratory group & & & RVRG \\
\hline Nucleus of Roller & + & & Ro \\
\hline Hypoglossal nucleus geniohyoid part & + & & $12 \mathrm{GH}$ \\
\hline Inferior olive, dorsal nucleus & ++ & & IOD \\
\hline Inferior olive, subnuclei A, B and C of medial nucleus & ++ & & IOA; IOB and IOC \\
\hline Inferior olive, cap of Kooy & + & & IOK \\
\hline Inferior olive, beta subnucleus & + & & $\mathrm{IOBe}$ \\
\hline Tectospinal tract & + & & ts \\
\hline Raphe pallidus nucleus & ++ & & Rpa \\
\hline
\end{tabular}

The GLP-1R-immunoreactive areas were ranked into four categories based on the density of immunoreactive fibers from "+", meaning low level to " ++++ " meaning "very high" level, and based on the density of immunoreactive perikarya from *meaning low to ***meaning high level
The presence of GLP-1R on axon terminals suggests that GLP-1 signaling may regulate the activity of presynaptic terminals and may modulate both GABA and glutamate release. Since the elevation of intracellular cAMP level is one of the main mediators of GLP-1R signaling (Rowlands et al. 2018; Kawatani et al. 2018; Oride et al. 2017), and cAMP is known to increase the release probability in presynaptic terminals (Chen and Regehr 1997), it is likely that GLP-1 and/or GLP-1 agonists increase the activity of the GLP-1R-containing presynaptic terminals. This hypothesis is supported by the findings of Rebosio et al. (2018) demonstrating that the GLP-1 agonist exendin-4 increases the GABA and aspartate release from hippocampal synaptosomal preparations, and also by our observation demonstrating facilitation of the synaptic input of POMC neurons by GLP-1 signaling (Péterfi 2020). Axonal localization of the receptor was also observed in the mouse brain indicating that the potential presynaptic action of GLP-1 signaling is not a species-specific feature.
At the ultrastructural level, most of the GLP-1R-imunoreactivity was observed in association to extrasynaptic membranes. This localization suggests that the ligand of this receptor is either released extrasynaptically from axons of GLP-1-synthesizing neurons and reach its receptor by volume transmission or it originates primarily from the peripheral blood. As GLP-1R agonists readily enter the ME-ARC and the NTS-AP regions (Ast et al. 2020; Gabery et al. 2020; Secher et al. 2014), it is likely that GLP-1 can also access these brain regions from the circulation and can bind to the extrasynaptic receptors.

We also observed GLP-1R in association with small clear and dense-core synaptic vesicles. The role of the receptor in these vesicles is currently unknown. However, as the GLP-1R is a surface receptor, we hypothesize that GLP-1R is not functioning in these vesicles, rather the receptor is transported in the vesicles to the cell membrane where it can be activated by its extracellular ligand. 

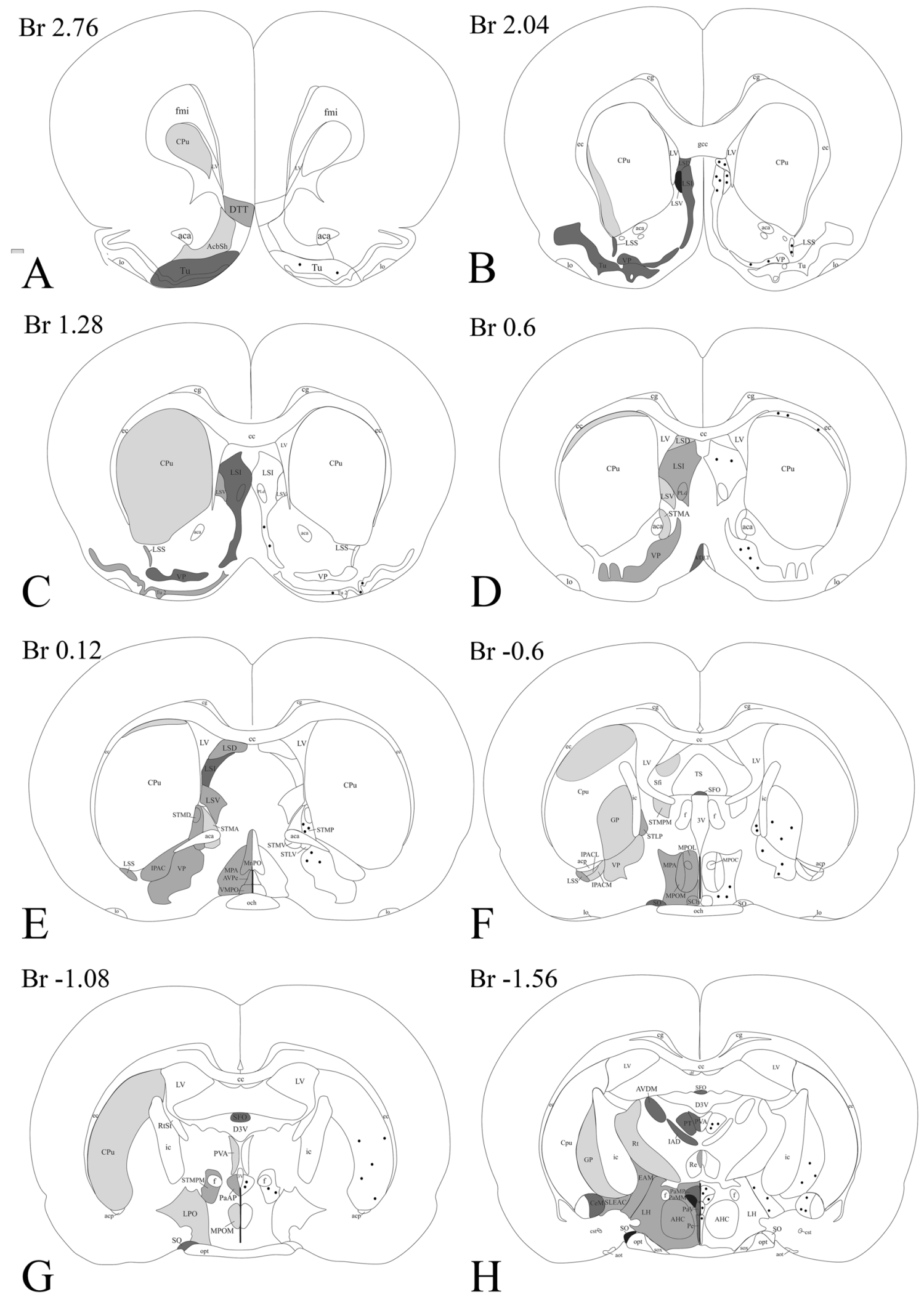

Fig. 3 Schematic illustration of the distribution of GLP-1R-IR processes (left side) and perikarya (right side) in the rat brain mapped

region where GLP-1R perikarya are present. The distance of the coronal plans from the Bregma is shown above the maps. The data is based on the sections of three rat brains in which the distribution of GLP-1R-immunreactivity was similar. 

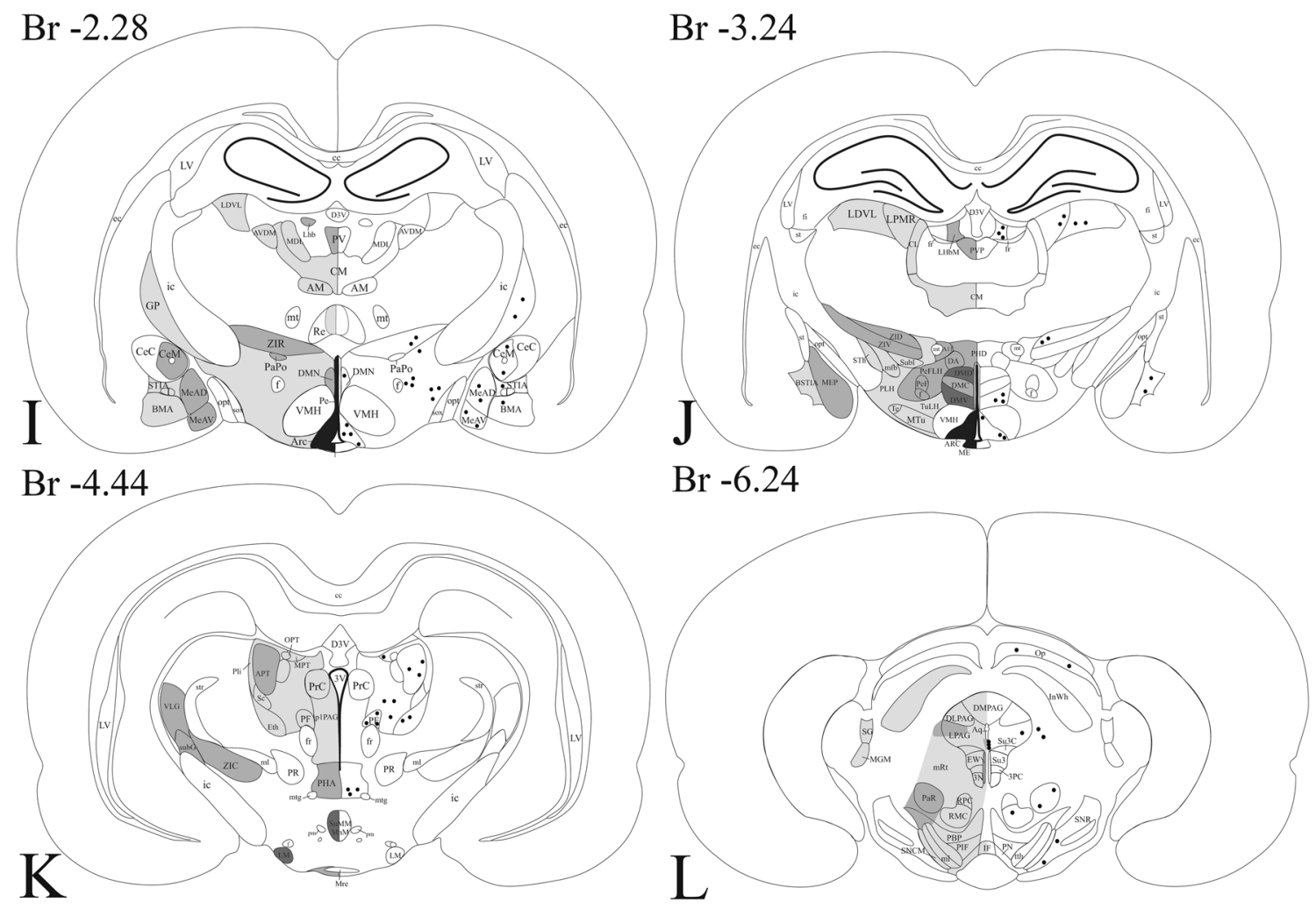

$\mathrm{Br}-7.2$

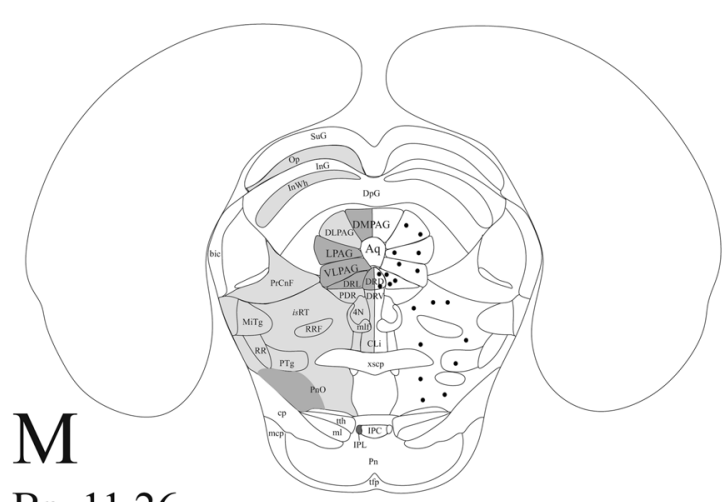

$\mathrm{Br}-11.26$

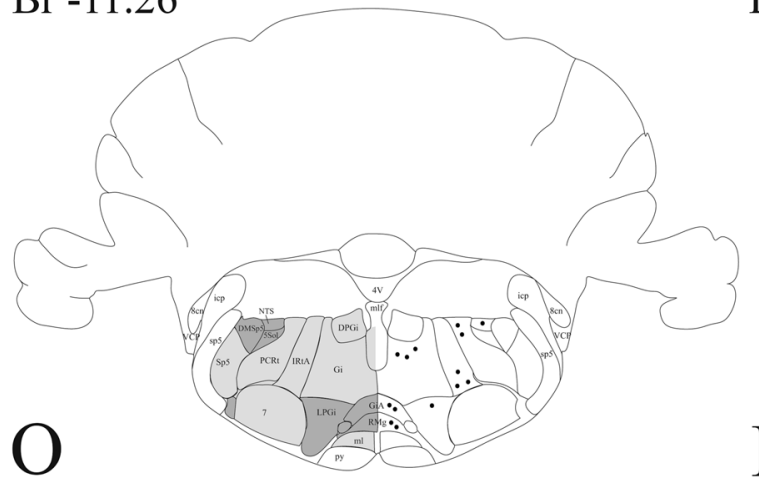

$\mathrm{Br}-9.12$
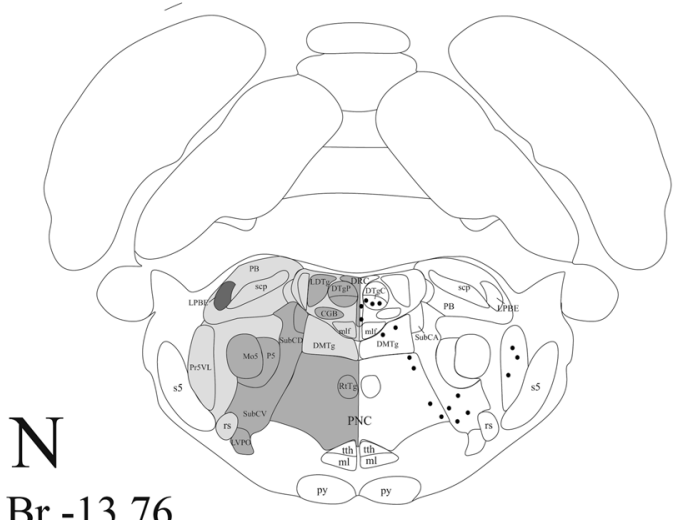

$\mathrm{P}$

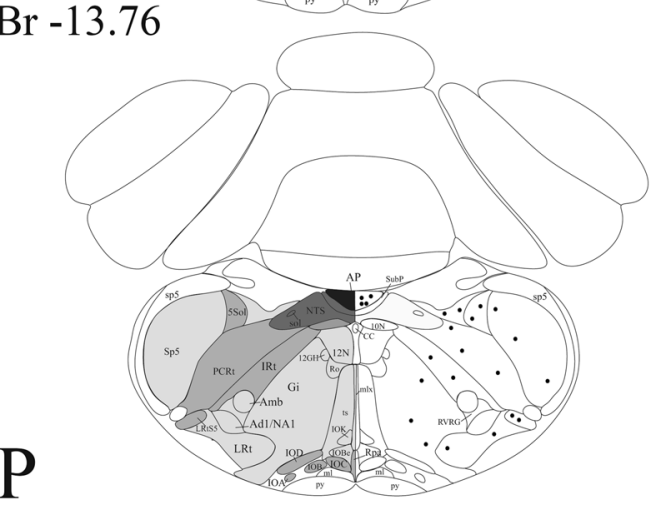

Fig. 3 (continued) 


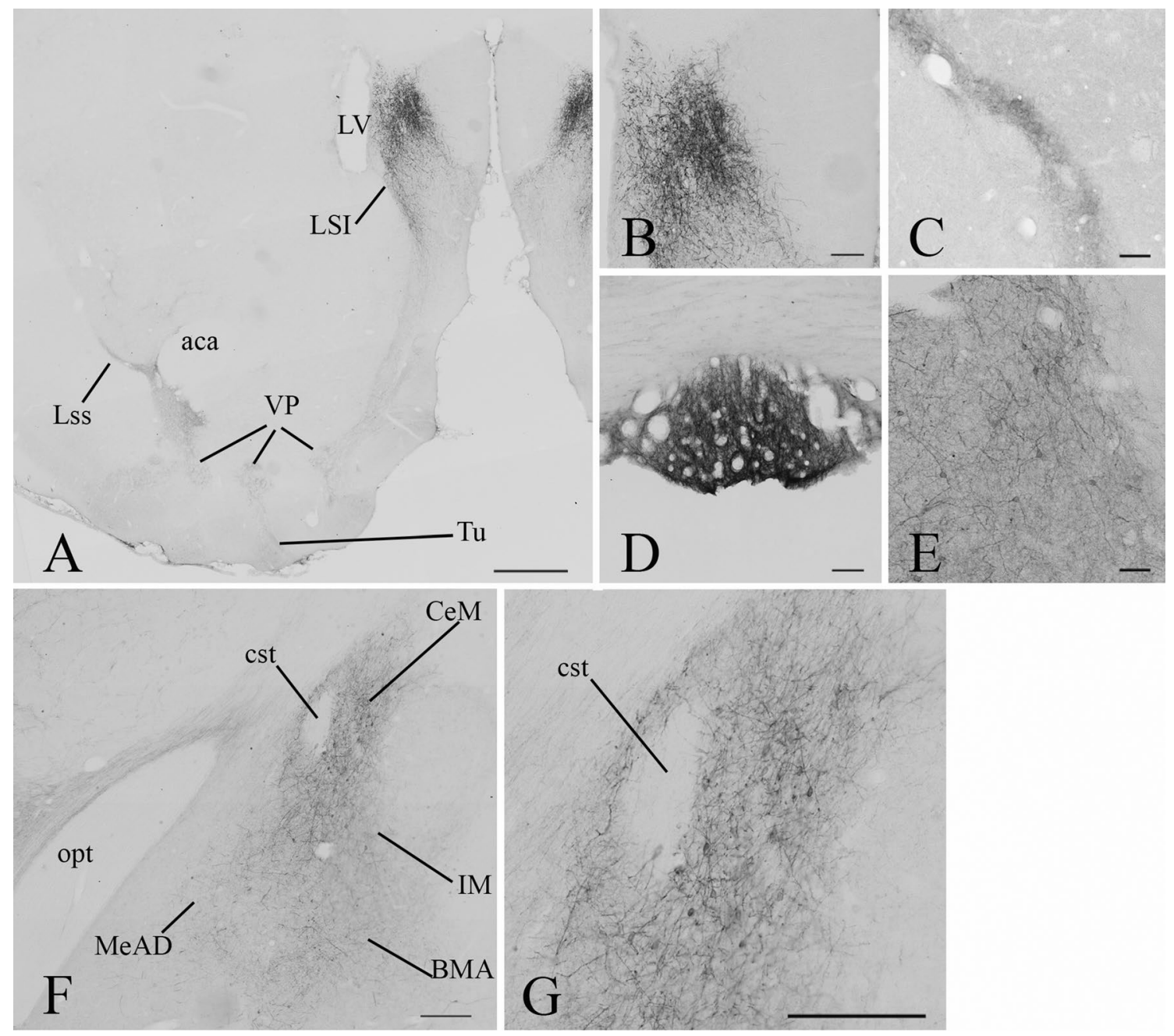

Fig. 4 Distribution of GLP-1R-IR elements in the telencephalon. Low magnification image (a) illustrates the distribution of GLP-1R-immunoreactivity at the level of the intermediate part of the lateral septal nucleus (LSI) and the ventral pallidum (VP). Very dense network of GLP-1R-IR processes is observed in the LSI. Dense network of GLP$1 R$-IR fibers is also present in the VP and the lateral stripe of striatum (Lss), but the level of immunoreactivity is slightly lower than in the LSI. Lower intensity GLP1R-IR signal is observed in processes in the olfactory tubercle (Tu). Higher magnification images illustrate the GLP-1R-immunoreactivity in the LSI (b) and LSS (c). Very high level of GLP-1R-immunoreactivity is present in the subfornical organ (d). Large number of GLP-1R-IR perikarya and processes

We have observed a widespread distribution of the GLP-1R-immunoreactive profiles both in the forebrain and the brainstem. The highest density of the GLP1R-immunoreactivity was found in circumventricular organs including the area postrema, ME, subfornical organ and the OVLT. The presence of GLP-1R in these brain regions is intriguing. The GLP-1 neurons do not project to these areas ( $\mathrm{Gu}$ et al. 2013), but the circumventricular organs are located outside of the blood-brain barrier suggesting that GLP-1 of peripheral origin could be the are observed in the bed nucleus of stria terminalis (BNST, e). Low magnification image illustrates the GLP-1R-mmunoreactivity in the amygdala (f). Large number of GLP-1R-IR perikarya and fibers are present in the medial part of the central amygdaloid nucleus $(\mathrm{CeM})$, while less immunoreaktive perikarya and somewhat less dense fiber network are observed in the anterodorsal part of the medial amygdaloid nucleus (MeAD), the anterior part of the basomedial amygdala (BMA) and the main intercalated amygdaloid nucleus (IM). Higher magnification image (g) illustrates the GLP-1R-IR elements in the CeM. aca anterior commissure, cst commissural stria terminalis, $L V$ lateral ventricle, opt optic tract

ligand of these receptors. Indeed, binding of peripherally administered GLP-1 to neurons of the subfornical organ and the area postrema has been demonstrated (Orskov et al. 1996). In the external zone of the median eminence, where the axons of hypophysiotropic neurons terminate, GLP-1R-immunoreactivity heavily labels the surface of axon terminals. Thus, it is likely that peripheral GLP-1 or GLP-1R agonists can regulate the release of hypophysiotropic hormones into the portal capillaries and, therefore, may regulate the activity of neuroendocrine axes. In the 


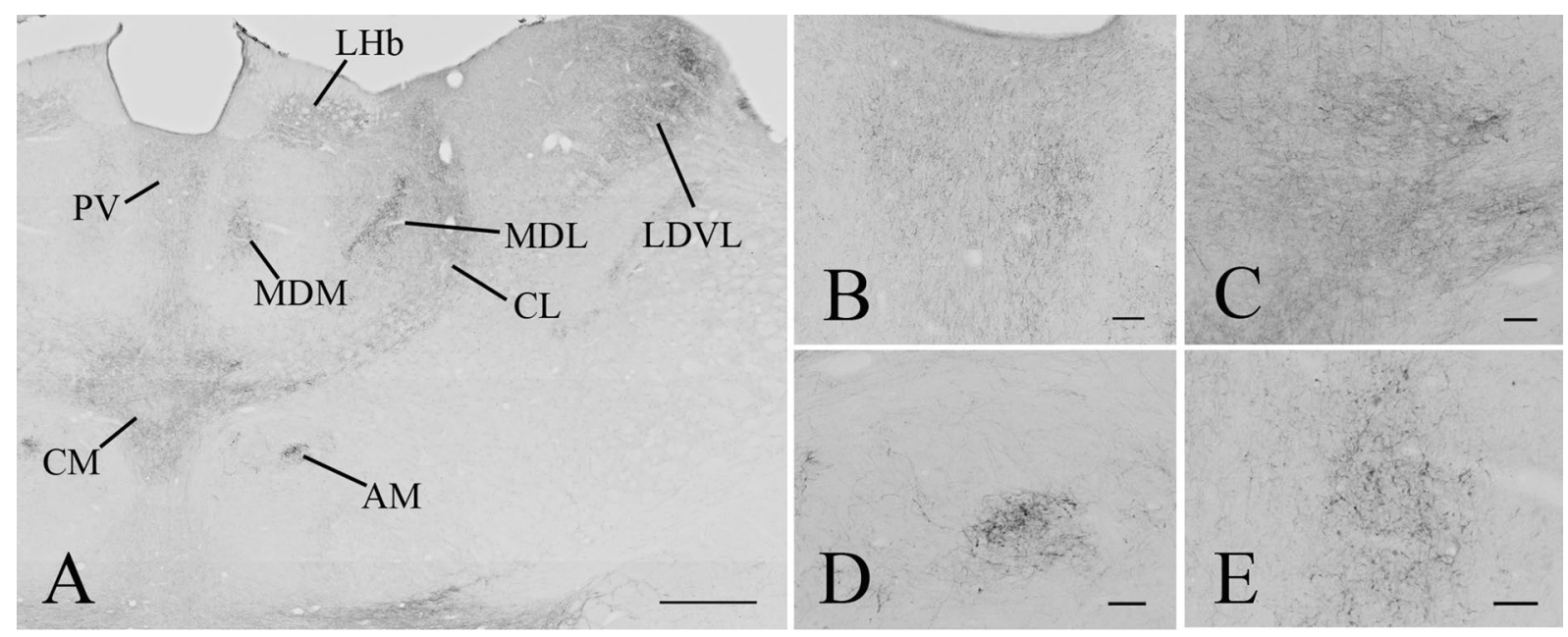

Fig. 5 Distribution of GLP-1R-immunoreactivity in the thalamus. Low magnification image illustrates the distribution of GLP-1R-IR elements in the thalamus (a). Dense network of GLP-1R-IR fibers can be seen in the paraventricular (PV), central medial (CM), centrolateral (CL), medial (MDM) and lateral parts of the mediodorsal

ME, GLP-1R-immunoreactivity was not observed in the $\beta 2$ tanycytes. Thus, it is unlikely that these tanycytes are involved in the transport of GLP-1 from the ME to the CSF or to the ARC in the rat. The presence of the receptor, however, was not studied in all subtypes of tanycytes, so we were not able to confirm the expression of GLP$1 \mathrm{R}$ in $\alpha$-tanycytes previously suggested to be involved in the transport of GLP-1R agonists into the ARC in mice (Gabery et al. 2020).

The cells of the blood-brain-barrier free AP can also be accessible for peripheral GLP-1 (Orskov et al. 1996). In the AP, the majority of perikarya and dendrites and numerous axons are almost completely ensheethed by silver grains labeling the GLP-1R-immunoreactivity suggesting that GLP-1 may influence directly the neurons of the area postrema, but it can also influence the input of these neurons. Indeed, it was shown by Kawatani et al. (2018) by patch-clamp electrophysiology that GLP-1 directly depolarizes the neurons of the area postrema and increases their firing. Furthermore, lesioning of area postrema markedly decreases the effect of peripherally administered GLP-1R agonist exendin- 4 on the neuronal activation in a number of brain regions like in the ventrolateral medulla, ARC and parabrachial nucleus, indicating that the area postrema mediates the GLP-1 signaling toward important energy homeostasis related brain regions (Baraboi et al. 2010). Intriguingly, however, lesion of the AP does not prevent the inhibitory effect of exendin-4 on the food intake (Baraboi et al. 2010) and also does not prevent the body weight reduction induced by the long acting GLP-1R agonist liraglutide (Secher et al. 2014). These data indicate that the AP mediates central
(MDL) thalamic nuclei, the anteromedial thalamic nucleus (AM), the ventrolateral part of the laterodorsal thalamic nucleus (LDVL and in the lateral habenular nucleus. Higher magnification images show the GLP-1R-IR elements in the PV (b), CM (c), AM (d) and MDM (e). Scale bars are $500 \mu \mathrm{m}$ on (a) and $50 \mu \mathrm{m}$ on $(\mathbf{b}-\mathbf{e})$

effects of GLP-1, but the role of the AP is not indispensable for the GLP-1 signaling induced regulation of food intake and body weight.

In the vicinity of the area postrema, the NTS is also densely labeled with GLP-1R-immunoreactivity. In this nucleus, the receptor was found in dendrites and in axons suggesting that GLP-1 may have a direct effect on the NTS neurons, but can also modulate the input of these cells. Interestingly, in contrast to other studied brain regions, the GLP-1R-immunoreactivity was primarily observed inside the neuronal profiles and not on their surface. As intra-NTS administration of GLP-1R agonist regulates food intake and hedonic values of food (Richard et al. 2015), the GLP-1R is obviously functional in this nucleus despite its primarily intracellular localization. GLP-1R is known to internalize after ligand binding (Fletcher et al. 2018), thus the high level of intracellular GLP-1R in this nucleus may suggest that the ligand occupancy of the GLP-1R can be relatively high in this nucleus. Although NTS is inside the blood-brain-barrier, peripheral hormones, like leptin, and ghrelin have been shown to influence energy homeostasis by acting directly on NTS neurons (Grill and Hayes 2012) indicating that peripheral hormones, including GLP-1, can enter this nucleus. Alternatively, GLP-1 released from the local proglucagon neurons may also act on the GLP-1R in this nucleus.

Very high levels of GLP-1R-immunoreactivity was present in the ARC, another brain region known to function as a sensor of peripheral energy homeostasis (Morton et al. 2006). Like in the AP, perikaryonal, dendritic and axonal localization of the GLP-1 receptor was observed in this nucleus. Since there are only very few GLP-1 containing 

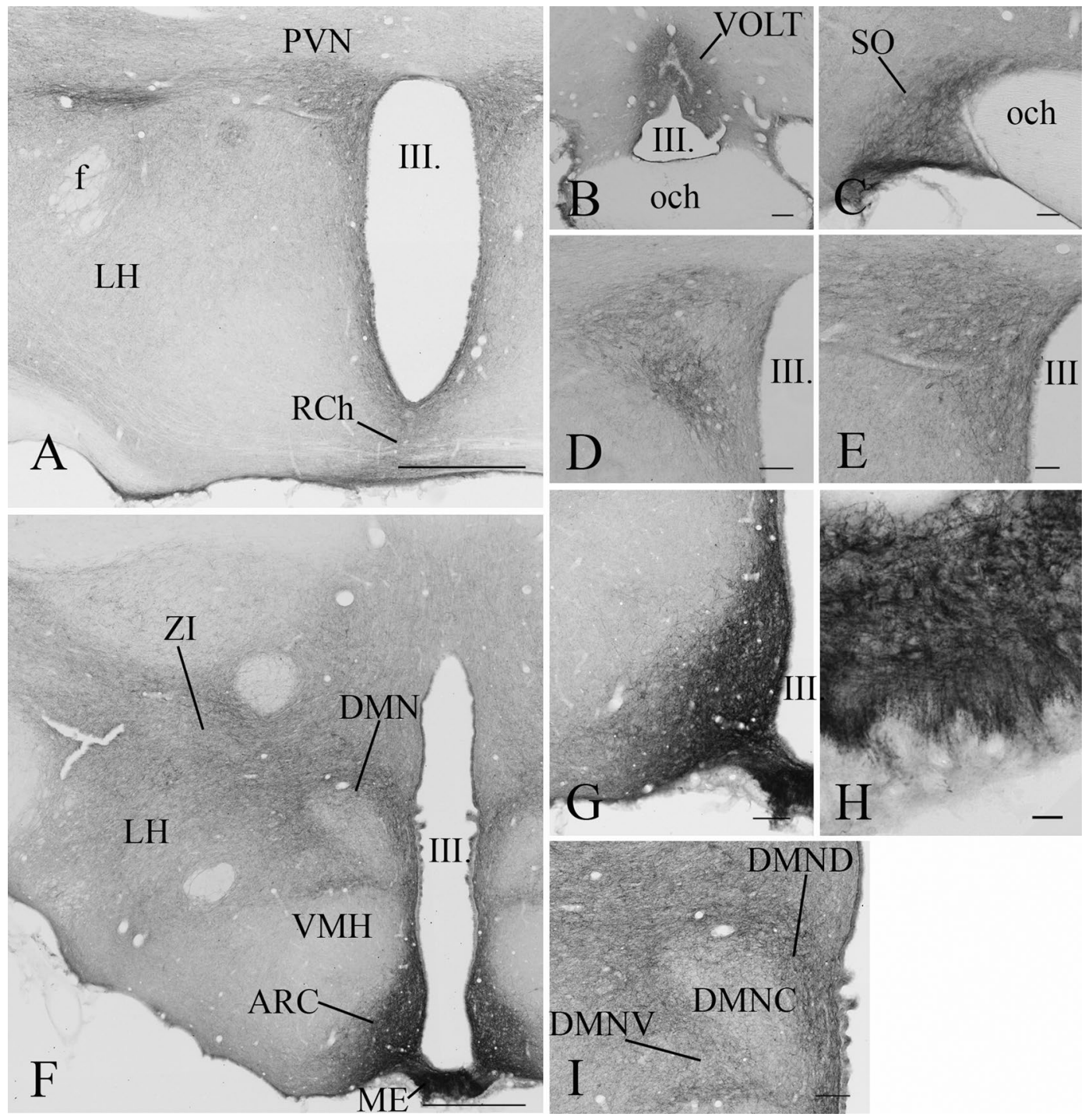

Fig. 6 Distribution of the GLP-1R-immunoreactivity in the hypothalamus. A low magnification image (a) illustrates the distribution of GLP-1R-immunoreactive profiles at the level of the hypothalamic paraventricular nucleus (PVN). Dense network of GLP-1R-IR fibers can be seen in the PVN, the periventricular area and in the retrochiasmatic area (RCh). Less dense fiber network can be also seen in the lateral hypothalamus (LH). GLP-1R-IR perikarya is present in the PVN. Dense network of GLP-1R-IR fibers is also present in the vascular organ of laminae terminalis (VOLT) (b). The supraoptic nucleus (SO) (c) is filled with GLP-1R-IR processes, while both GLP-1R-IR perikarya and fibers are present in the mid (d) and caudal levels (e) of the PVN. Low magnification image (f) illustrates the distribution of the GLP-1R-IR profiles at the level of hypothalamic dorsomedial

nucleus (DMN) and the arcuate nucleus (ARC). Note the very high density of the GLP-1R-immunoreactivity in the ARC and the median eminence (ME). Dense network of GLP-1R-IR profiles is also present in the DMN, zona incerta (ZI) and in the LH. GLP-1R is absent from the ventromedial hypothalamic nucleus (VMH). Higher magnification images demonstrate the presence of the GLP-1R-IR structures in the $\operatorname{ARC}(\mathbf{g})$, the ME (h) and in the DMN (i). Within the DMN, dense fiber network is present in the ventral (DMNV) and dorsal (DMND) parts of the nucleus, while the density of immunoreactive fibers is much lower in the compact part of the nucleus (DMNC). III Third ventricle, $f$ fornix, och optic chiasm. Scale bars are $500 \mu \mathrm{m}$ on a and $\mathbf{f} ; 100 \mu \mathrm{m}$ on $\mathbf{d}, \mathbf{g}, \mathbf{i}, 50 \mu \mathrm{m}$ on $\mathbf{c}, \mathbf{e}$ and $20 \mu \mathrm{m}$ on $\mathbf{h}$

axons in the ARC (Larsen et al. 1997), it is likely that the GLP-1R-containing neuronal profiles are primarily regulated by peripheral GLP-1 in this nucleus. Within the ARC, the anorexigenic POMC neurons are known to be regulated by GLP-1 signaling (Secher et al. 2014; Gabery et al. 2020). POMC neurons accumulate the GLP-1R agonist liraglutide after its peripheral administration, furthermore, GLP-1

depolarizes these neurons and increases their firing rate (Secher et al. 2014) suggesting that the effect of GLP-1 and its agonists on the POMC neurons may contribute to the anorexigenic effect of these compounds (Secher et al. 2014). In the ARC, however, far more neurons seem to contain the GLP-1R and/or are innervated by GLP-1R-containing axons, therefore, further studies are needed to understand 

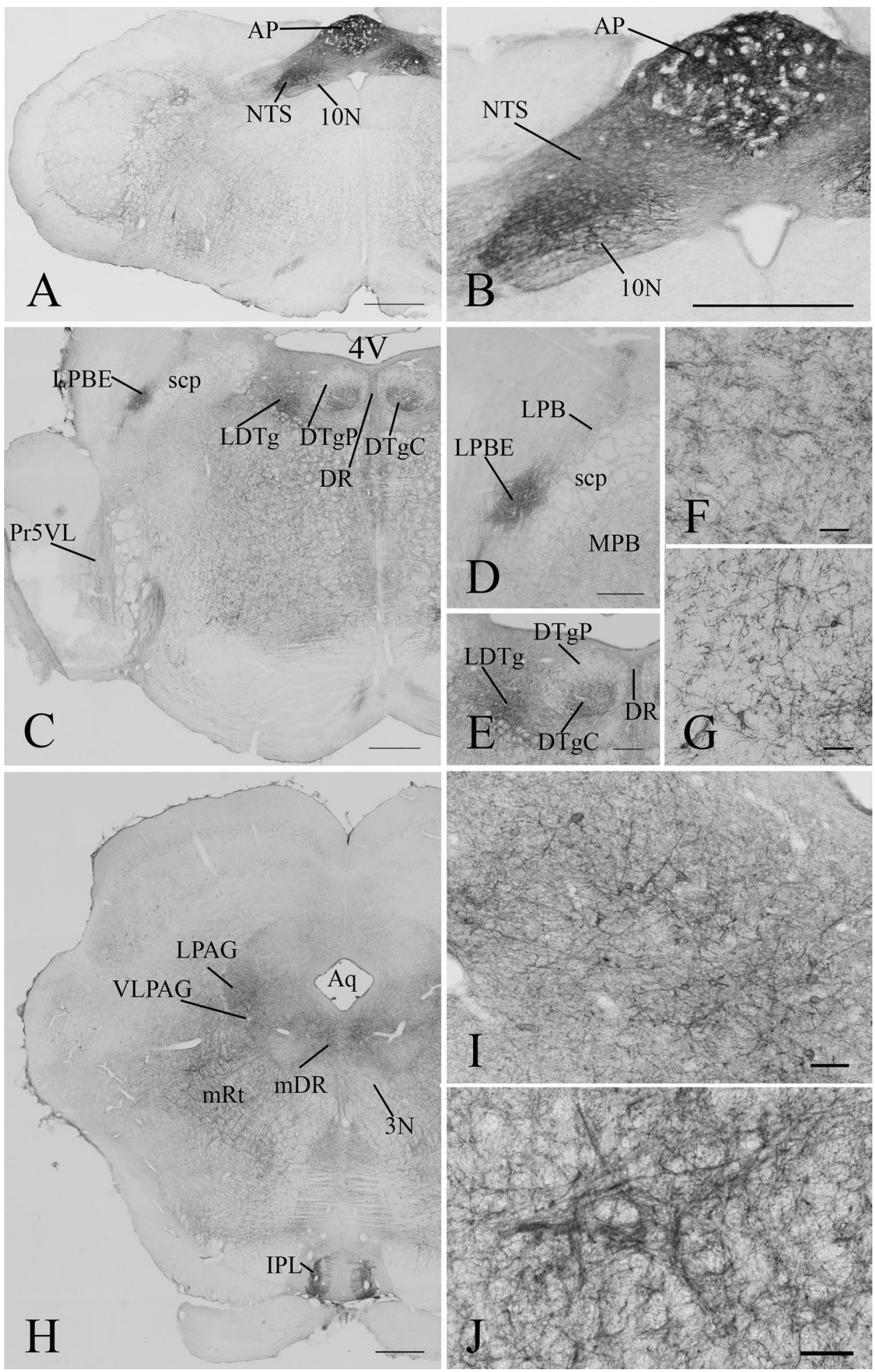

the chemotype and function of GLP-1 target neurons in this nucleus.

Although circumventricular organs and the neighboring ARC and NTS contain the highest density of GLP-1R, there is a far more widespread distribution of this receptor. The presence of GLP-1R in energy homeostasis related nuclei, like the DMN, PVN and BNST, and in reward regions such as nucleus accumbens and ventral pallidum is in accordance with the known function of GLP-1 in the regulation of reward processes (Hayes and Schmidt 2016).

GLP-1 receptors are also observed in regions that are not directly related to the regulation of energy homeostasis such 
4Fig. 7 Distribution of GLP-1R in the brainstem. At the level of the medulla (a) very high level of GLP-1R-immunoreactivity is present in the area postrema (AP) and the the nucleus of the solitary tract (NTS). GLP-1R-immunoreactivity can also be observed in the dorsal motor nucleus of the vagus $(10 \mathrm{~N})$ and in the reticular nuclei. Higher magnification image (b) illustrates the GLP-1R-immunoreactivity in the AP, NTS and $10 \mathrm{~N}$. In the pons (c), widespread distribution of the GLP-1R-IR profiles was observed at the level of the parabrachial nucleus (PB). This nucleus is also shown at higher magnification (d). GLP-1R-IR fibers are observed in both the medial (MPB) and lateral parts (LPB) of the nucleus, however, the external part of the LPB (LPBE) contains a very dense network of GLP-1R-IR fibers. In the dorsal pontin tegmentum, shown at higher magnification at (e), high density of GLP-1R-IR fibers is present in the laterodorsal tegmental nucleus (LDTg). High number of GLP-1R-IR perikarya is observed in the central part of the dorsal tegmental nucleus (DTgC), while only GLP-1R-IR fibers are seen in the dorsal part of the nucleus (DTgP). The dorsal raphe (DR) also contains GLP1R-IR fibers. GLP-1R-IR fibers and scattered perikarya can be seen in the reticular formation and the ventrolateral part of the principal sensory trigeminal nucleus (Pr5VL). Higher magnification images of the caudal part of the pontin reticular nucleus (PNC) and the ventral part of the subcoerules $(\mathrm{SubCV})$ are shown on (f) and (g), respectively. Low magnification image (h) illustrates the GLP-1R-IR elements in the mesencephalon at the level of the oculomotor nucleus (3 N). High level of GLP$1 \mathrm{R}$-immunoreactivity is observed in the lateral part of the interpeduncular nucleus (IPL). Dense network of GLP-1R-IR fibers is present in the lateral (LPAG) and ventrolateral (VLPAG) periaqueductal gray, in the mesencephalic dorsal raphe (mDR) and the mesencephalic reticular formation (mRt). GLP-1R-immunoreactive fibers are also present in the oculomotor nucleus, but in much lower density. In addition to fibers GLP-1R-IR perikarya are also present in the LPAG, VLPAG, $\mathrm{mDR}$ and $\mathrm{mRt}$. Higher magnification images show the GLP$1 \mathrm{R}-\mathrm{IR}$ elements in the DR (i) and mRt (j). $4 \mathrm{~V}$ 4th ventricle, $A q$ cerebral aqueductus, $s c p$ superior cerebellar peduncle Sc. Scale bars are $500 \mu \mathrm{m}$ on $\mathbf{a}-\mathbf{c}$ and $\mathbf{h} ; 200 \mu \mathrm{m}$ on $\mathbf{d}$ and $\mathbf{e} ; 50 \mu \mathrm{m}$ on $\mathbf{f}, \mathbf{g}, \mathbf{i}$ and $\mathbf{j}$

as thalamic nuclei, lateral septum and reticular nuclei of the brainstem suggesting that GLP-1 signaling has much more diverse functions in the brain.

Despite the fact that GLP-1 effect has been detected in the hippocampus and cortex (Hsu et al. 2015; Csajbok et al. 2019), low level of GLP-1R-immunoreactivity with variable pattern and density was observed in these areas, therefore, further studies with more sensitive antibodies and/or methods are necessary to elucidate the distribution of GLP-1R protein in hippocampal and cortical areas. The very low level of GLP-1R-immunoreactivity in the rat hippocampus is in contrast to the relatively high level of GLP-1R-immunoreactivity in the mouse hippocampus (Jensen et al. 2018) suggesting a strong species difference of the GLP-1R signaling in this brain region.

In contrast to these brain regions, GLP-1R-immunoreactivity very strongly labeled the Purkinje cells and the molecular layer of the cerebellum suggesting that the GLP-1 signaling may have an important effect in the regulation of cerebellar function.

The described distribution of GLP-1R-immunoreactivity is highly similar to the distribution of GLP-1 and exendin-4 binding sites observed by Goke et al. (1995) using unfixed sections of rat brain. They found the highest receptor binding in the lateral septum, in the circumventricular areas and in regions located around the circumventricular areas where we found the highest density of receptor immunoreactivity. In addition, they also did not observe binding in cortical areas and the hippocampus, where we observed only very faint immunoreaction signal that could not be unequivocally differentiated from the background signal.

The observed distribution of the GLP-1R-IR perikarya is also similar to the distribution of the GLP-1R mRNA expressing neurons (Merchenthaler et al. 1999). A major difference is, however, that widespread distribution of GLP$1 \mathrm{R}$ mRNA was observed in the hippocampus of rats (Merchenthaler et al. 1999), while we observed only very faint immunoreaction signal in this brain area. We do not know whether the GLP-1R protein content of these cells is very low despite their readily detectable GLP-1R mRNA content, or if the protein is transported to axons that terminate outside the hippocampus. Alternatively, a special variant of the receptor could be expressed in the hippocampus that is not detected by the used antibody. The latter explanation, however, is unlikely due to the very minimal GLP-1 binding in the hippocampus.

The distribution of GLP-1R-IR profiles in the mouse brain was earlier described by Jensen et al. (2018). That study, however, focused primarily on the distribution of GLP-1R-IR perikarya and described the presence of GLP$1 \mathrm{R}$-IR fibers only in a few brains areas. In contrast, we observed a very widespread distribution of GLP-1R-IR fibers in the brain and using immuno-electron microscopy, we proved that these fibers are not only dendrites but GLP-1R also has presynaptic localization. As we also observed a

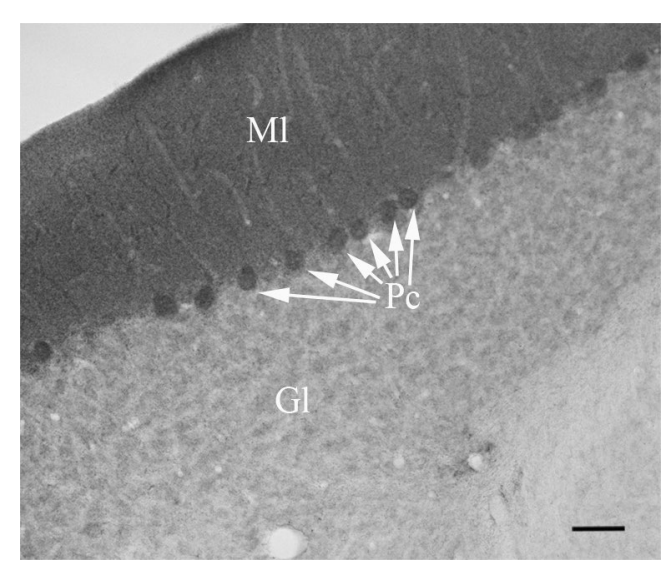

Fig. 8 Distribution of GLP-1R-immunoreactivity in the cerebellum. Punctuate GLP-1R-immunoreactivity labels the cell bodies of Purkinje cells (arrows) and the entire molecular layer. Low level of punctuate GLP-1R-immunoreactivity is also present in the granular layer. $G l$ granular layer, $M l$ molecular layer, $P c$ Purkinje cells; scale bar $=50 \mu \mathrm{m}$ 

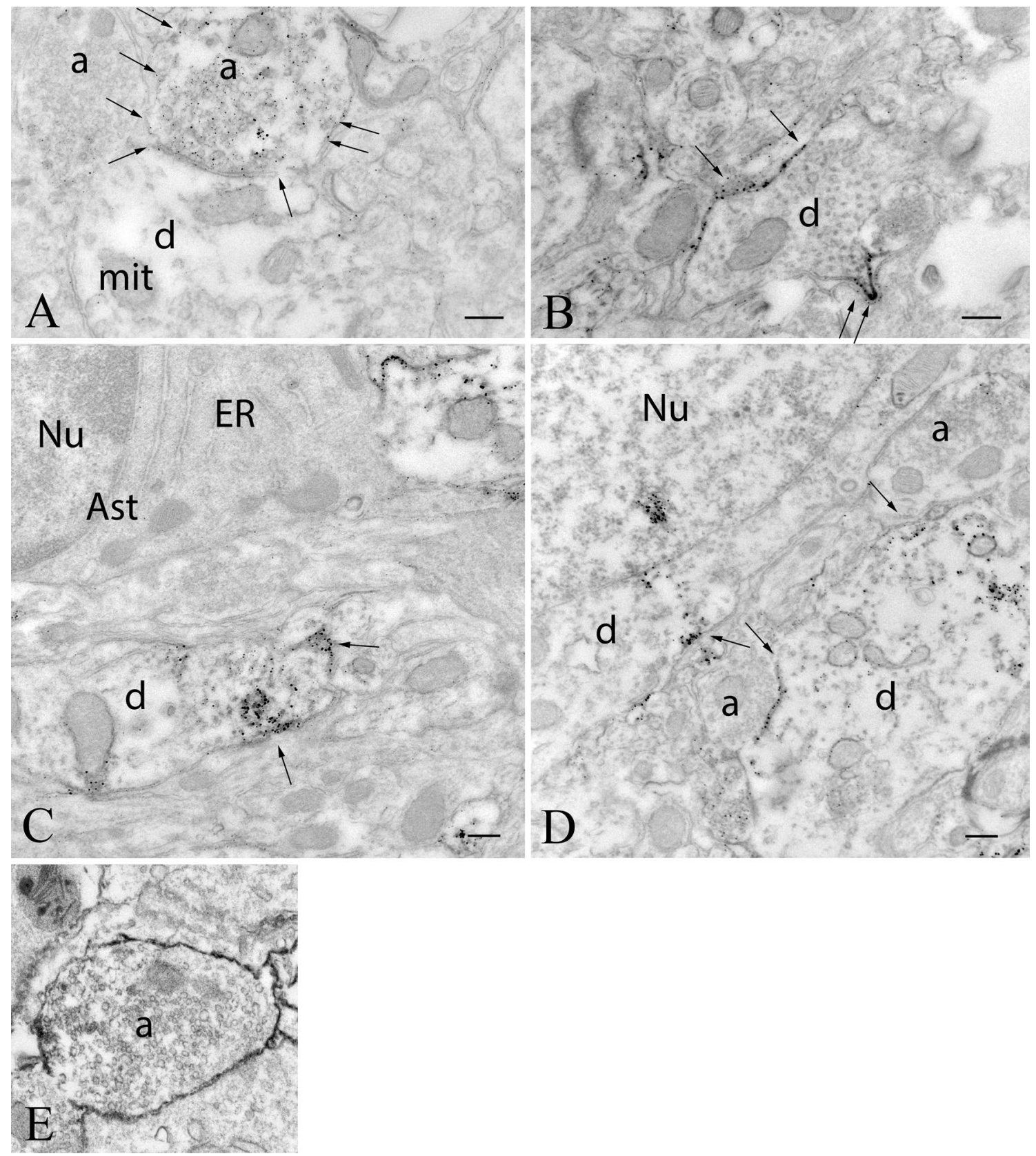

Fig. 9 Ultrastructural localization of GLP-1R in the arcuate nucleus. GLP-1R-immunoreactivity is labeled with electron-dense silver particles. In this nucleus of rats, the GLP-1R-immunoreactivity is present in axons (a), dendrites (b-d) and neuronal perikarya (d), while GLP$1 \mathrm{R}$-immunoreactivity was not observed in the perikarya of astrocytes (c). a Illustrates a GLP-1R-immunoreactive axon (arrows) forming symmetric type synapse on an unlabeled dendrite. b Demonstrates the presence of silver grains labeling GLP-1R-immunoreactivity on the membrane of a dendrite (arrows). c Illustrates a dendrite where

very dense network of GLP-1R-IR fibers in the mouse brain and proved the presence of the receptor in axons of mouse hypothalamus, we believe that this discrepancy of the two description is not simply due to species differences. Jensen
GLP-1R is present in both the cytoplasm and on the cell membrane (arrows). The astrocyte shown by this image is unlabeled. d Shows GLP-1R-IR perikaryon and dendrite. In both cases, the immuoreactivity is associated to both the cytoplasm and the cell membrane (arrows). e Demonstrates that axonal localization of the GLP-1R is also present in the ARC of mice. $a$ axon, Ast astrocyte, $d$ dendrite, $E R$ endoplasmatic reticulum, mit mitochondrium, $N u$ nucleus, scale bars $=0.25 \mu \mathrm{m}$

et al. (2018) performed their immunostaining on paraffinembedded tissues of mice perfused with 4\% PFA and used diaminobenzidine as chromogen. We did not test the effect of paraffin embedding, but in our preliminary studies, we 


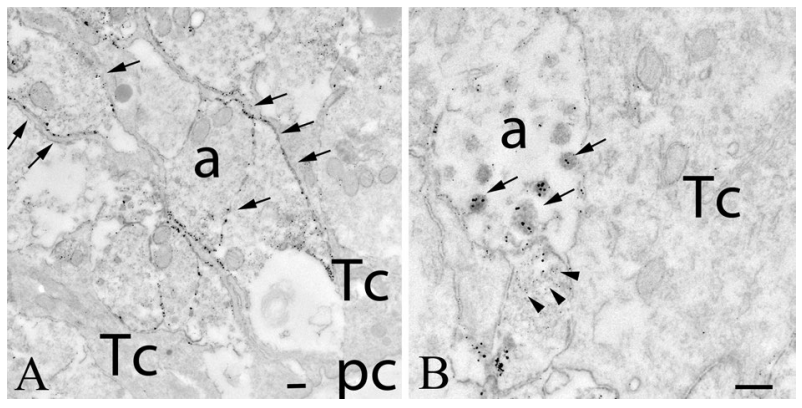

Fig. 10 Distribution of GLP-1R-immunoreactivity in the median eminence. In the external zone of the median eminence (a), numerous GLP-1R-IR axons (arrows) can be observed. The silver grains denoting the GLP-1R-immunoreactivity encircle the hypophysiotropic axon terminals in the vicinity of the portal capillaries. Silver grains were not observed in association with tanycyte processes. The association of the silver grains to dense core (arrows) and small clear (arrowheads) vesicles can also be observed (b). $a$ axon, $p c$ portal capillary, $T c$ tanycyte. Scale bars $=0.25 \mu \mathrm{m}$

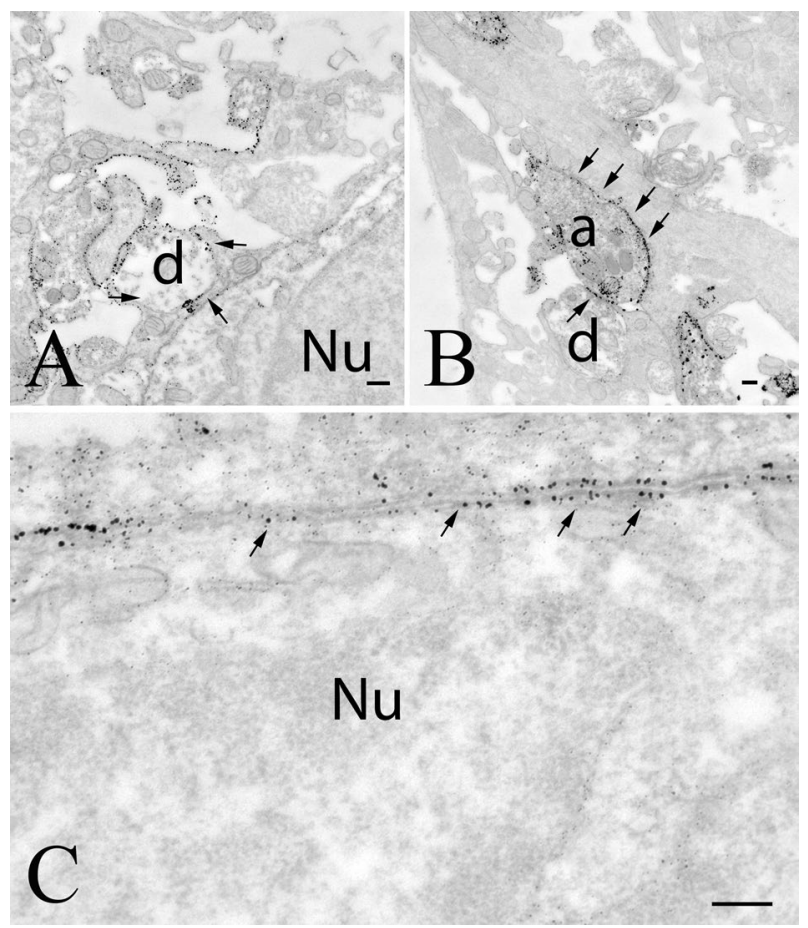

Fig. 11 GLP-1R in the area postrema. In this brain area, GLP-1R-immunoreactivity densely labels the surface of dendrites (a), axons (b) and perikarya (c). Arrows point to the silver grains labeling the GLP-1R-immunreactivity. $a$ axon, $d$ dendrite, $N u$ nucleus; scale bars $=0.25 \mu \mathrm{m}$

observed that the addition of $1 \%$ acrolein to the PFA solution highly improves the detection of GLP-1R with the used antibody. Therefore, we used this fixation method in our study. In addition, we used Ni-DAB developer that can also

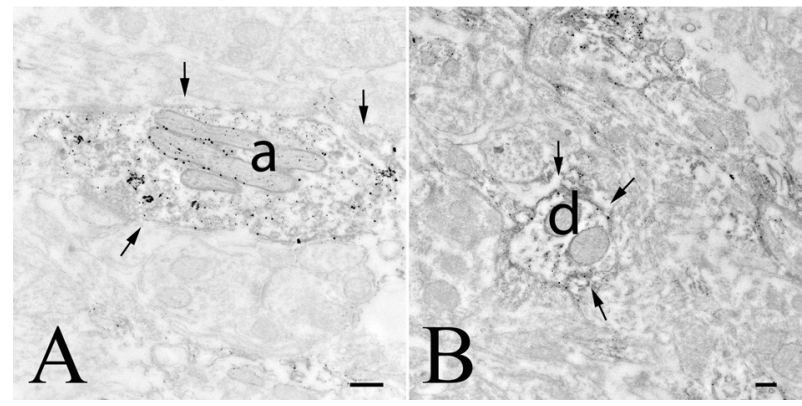

Fig. 12 GLP-1R-immunoreactivity in the NTS. In this nucleus, GLP-1R-immunoreactivity was primarily observed in axons (a, arrows) and dendrites (b, arrows). Note that the silver grains, denoting the GLP-1R-immunoreactivity were predominantly present in the cytoplasm of the labeled structures. $a$ axon, $d$ dendrite; scale bars $=0.25 \mu \mathrm{m}$

increase the sensitivity of immunocytochemistry compared to the use of diaminobenzidine.

In summary, we demonstrated a very widespread distribution of GLP-1R protein in the rat brain with the highest levels in the circumventricular organs and in the ARC and NTS. We demonstrated that in addition to the expected perikaryonal localization, GLP-1R is also present in axons suggesting that GLP-1 not only has direct effects on target neurons, but it can also regulate the presynaptic input of neuronal populations and may regulate neuroendocrine axes by influencing the activity of hypophysiotropic terminals.

Author contributions EF performed immunostaining and electron microscopy and was involved in the mapping. YR and ASz-Sz performed immunostaining. MGR and TE performed the rabbitization of the mouse monoclonal GLP-1R antibody. RS and BG performed experiments to prove the specificity of the used antibodies. CP and LBK initiated the studies and were involved in manuscript preparation. $\mathrm{CF}$ planed the studies, was involved in the mapping and manuscript preparation.

Funding Open access funding provided by ELKH Institute of Experimental Medicine. This work was supported by Grants from the Hungarian National Brain Research Program (2017-1.2.1-NKP-2017-00002), EU H2020 THYRAGE no. 666869.

Data availability (Data transparency) All data associated with this study are present in the paper.

Code availability (Software application or custom code) not applicable.

\section{Compliance with ethical standards}

Conflicts of interest M.G.R, T.E, C.P. and L.B.K. are shareholders and current employees of Novo Nordisk A/S. C.F. has received funding from Novo Nordisk A/S. A.Sz-Sz., E.F., Y.R. S.R and B.G declare no competing interest. 
Open Access This article is licensed under a Creative Commons Attribution 4.0 International License, which permits use, sharing, adaptation, distribution and reproduction in any medium or format, as long as you give appropriate credit to the original author(s) and the source, provide a link to the Creative Commons licence, and indicate if changes were made. The images or other third party material in this article are included in the article's Creative Commons licence, unless indicated otherwise in a credit line to the material. If material is not included in the article's Creative Commons licence and your intended use is not permitted by statutory regulation or exceeds the permitted use, you will need to obtain permission directly from the copyright holder. To view a copy of this licence, visit http://creativecommons.org/licenses/by/4.0/.

\section{References}

Andersen A, Lund A, Knop FK, Vilsboll T (2018) Glucagon-like peptide 1 in health and disease. Nat Rev Endocrinol 14(7):390-403. https://doi.org/10.1038/s41574-018-0016-2

Ast J, Arvaniti A, Fine NHF, Nasteska D, Ashford FB, Stamataki Z, Koszegi Z, Bacon A, Jones BJ, Lucey MA, Sasaki S, Brierley DI, Hastoy B, Tomas A, D'Agostino G, Reimann F, Lynn FC, Reissaus CA, Linnemann AK, D'Este E, Calebiro D, Trapp S, Johnsson K, Podewin T, Broichhagen J, Hodson DJ (2020) Super-resolution microscopy compatible fluorescent probes reveal endogenous glucagon-like peptide-1 receptor distribution and dynamics. Nat Commun 11(1):467. https://doi.org/10.1038/ s41467-020-14309-w

Baggio LL, Drucker DJ (2007) Biology of incretins: GLP-1 and GIP. Gastroenterology 132(6):2131-2157. https://doi.org/10.1053/j. gastro.2007.03.054

Baraboi ED, Smith P, Ferguson AV, Richard D (2010) Lesions of area postrema and subfornical organ alter exendin-4-induced brain activation without preventing the hypophagic effect of the GLP-1 receptor agonist. Am J Physiol Regul Integr Comp Physiol 298(4):R1098-1110. https://doi.org/10.1152/ajpre gu.00326.2009

Bhatti MM, Cai AG, Theunissen JW (2019) Binding affinities of human IgG1 and chimerized pig and rabbit derivatives to human, pig and rabbit Fc gamma receptor IIIA. PLoS ONE 14(7):e0219999. https ://doi.org/10.1371/journal.pone.0219999

Chen C, Regehr WG (1997) The mechanism of cAMP-mediated enhancement at a cerebellar synapse. J Neurosci 17(22):8687-8694

Chen YC, Taylor AJ, Verchere CB (2018) Islet prohormone processing in health and disease. Diabetes Obes Metab 20(Suppl 2):64-76. https://doi.org/10.1111/dom.13401

Cork SC, Richards JE, Holt MK, Gribble FM, Reimann F, Trapp S (2015) Distribution and characterisation of glucagon-like peptide-1 receptor expressing cells in the mouse brain. Mol Metab 4(10):718-731. https://doi.org/10.1016/j.molmet.2015.07.008

Csajbok EA, Kocsis AK, Farago N, Furdan S, Kovacs B, Lovas S, Molnar G, Liko I, Zvara A, Puskas LG, Patocs A, Tamas G (2019) Expression of GLP-1 receptors in insulin-containing interneurons of rat cerebral cortex. Diabetologia 62(4):717-725. https://doi. org/10.1007/s00125-018-4803-Z

Davies M, Pieber TR, Hartoft-Nielsen ML, Hansen OKH, Jabbour S, Rosenstock J (2017) Effect of oral semaglutide compared with placebo and subcutaneous semaglutide on glycemic control in patients with type 2 diabetes: a randomized clinical trial. JAMA 318(15):1460-1470. https://doi.org/10.1001/jama.2017.14752

Fabian RH, Ritchie TC (1986) Intraneuronal IgG in the central nervous system. J Neurol Sci 73(3):257-267. https://doi.org/10.1016/0022$510 x(86) 90150-4$
Fletcher MM, Halls ML, Zhao P, Clydesdale L, Christopoulos A, Sexton PM, Wootten D (2018) Glucagon-like peptide-1 receptor internalisation controls spatiotemporal signalling mediated by biased agonists. Biochem Pharmacol 156:406-419. https://doi. org/10.1016/j.bcp.2018.09.003

Gabery S, Salinas CG, Paulsen SJ, Ahnfelt-Ronne J, Alanentalo T, Baquero AF, Buckley ST, Farkas E, Fekete C, Frederiksen KS, Helms HCC, Jeppesen JF, John LM, Pyke C, Nohr J, Lu TT, Polex-Wolf J, Prevot V, Raun K, Simonsen L, Sun G, SzilvasySzabo A, Willenbrock H, Secher A, Knudsen LB (2020) Semaglutide lowers body weight in rodents via distributed neural pathways. JCI Insight. https://doi.org/10.1172/jci.insight.133429

Gerstein HC, Colhoun HM, Dagenais GR, Diaz R, Lakshmanan M, Pais P, Probstfield J, Riesmeyer JS, Riddle MC, Ryden L, Xavier D, Atisso CM, Dyal L, Hall S, Rao-Melacini P, Wong G, Avezum A, Basile J, Chung N, Conget I, Cushman WC, Franek E, Hancu N, Hanefeld M, Holt S, Jansky P, Keltai M, Lanas F, Leiter LA, Lopez-Jaramillo P, Cardona Munoz EG, Pirags V, Pogosova N, Raubenheimer PJ, Shaw JE, Sheu WH, Temelkova-Kurktschiev T (2019) Dulaglutide and cardiovascular outcomes in type 2 diabetes (REWIND): a doubleblind, randomised placebo-controlled trial. Lancet (London, England) 394(10193):121-130. https://doi.org/10.1016/s0140 $-6736(19) 31149-3$

Goke R, Larsen PJ, Mikkelsen JD, Sheikh SP (1995) Distribution of GLP-1 binding sites in the rat brain: evidence that exendin- 4 is a ligand of brain GLP-1 binding sites. Eur J Neurosci 7(11):22942300. https://doi.org/10.1111/j.1460-9568.1995.tb00650.x

Grill HJ, Hayes MR (2012) Hindbrain neurons as an essential hub in the neuroanatomically distributed control of energy balance. Cell Metab 16(3):296-309. https://doi.org/10.1016/j.cmet.2012.06.015

Gu G, Roland B, Tomaselli K, Dolman CS, Lowe C, Heilig JS (2013) Glucagon-like peptide-1 in the rat brain: distribution of expression and functional implication. J Comp Neurol 521(10):2235-2261. https://doi.org/10.1002/cne.23282

Hayes MR, Schmidt HD (2016) GLP-1 influences food and drug reward. Curr Opin Behav Sci 9:66-70. https://doi.org/10.1016/j. cobeha.2016.02.005

Heppner KM, Kirigiti M, Secher A, Paulsen SJ, Buckingham R, Pyke C, Knudsen LB, Vrang N, Grove KL (2015) Expression and distribution of glucagon-like peptide-1 receptor mRNA, protein and binding in the male nonhuman primate (Macaca mulatta) brain. Endocrinology 156(1):255-267. https://doi.org/10.1210/ en.2014-1675

Hsu TM, Hahn JD, Konanur VR, Lam A, Kanoski SE (2015) Hippocampal GLP-1 receptors influence food intake, meal size, and effort-based responding for food through volume transmission. Neuropsychopharmacology 40(2):327-337. https://doi. org/10.1038/npp.2014.175

Jensen CB, Pyke C, Rasch MG, Dahl AB, Knudsen LB, Secher A (2018) Characterization of the glucagonlike peptide-1 receptor in male mouse brain using a novel antibody and in situ hybridization. Endocrinology 159(2):665-675. https://doi.org/10.1210/ en.2017-00812

Kawatani M, Yamada Y, Kawatani M (2018) Glucagon-like peptide-1 (GLP-1) action in the mouse area postrema neurons. Peptides 107:68-74. https://doi.org/10.1016/j.peptides.2018.07.010

Larsen PJ, Tang-Christensen M, Holst JJ, Orskov C (1997) Distribution of glucagon-like peptide-1 and other preproglucagon-derived peptides in the rat hypothalamus and brainstem. Neuroscience 77(1):257-270

Liposits Z, Setalo G, Flerko B (1984) Application of the silver-gold intensified 3,3'-diaminobenzidine chromogen to the light and electron microscopic detection of the luteinizing hormone-releasing hormone system of the rat brain. Neuroscience 13(2):513-525 
Marso SP, Bain SC, Consoli A, Eliaschewitz FG, Jodar E, Leiter LA, Lingvay I, Rosenstock J, Seufert J, Warren ML, Woo V, Hansen O, Holst AG, Pettersson J, Vilsboll T (2016) Semaglutide and cardiovascular outcomes in patients with type 2 diabetes. N Engl J Med 375(19):1834-1844. https://doi.org/10.1056/NEJMoa1607141

Merchenthaler I, Lane M, Shughrue P (1999) Distribution of pre-proglucagon and glucagon-like peptide-1 receptor messenger RNAs in the rat central nervous system. J Comp Neurol 403(2):261-280

Morton GJ, Cummings DE, Baskin DG, Barsh GS, Schwartz MW (2006) Central nervous system control of food intake and body weight. Nature 443(7109):289-295. https://doi.org/10.1038/natur e05026

Muller TD, Finan B, Bloom SR, D’Alessio D, Drucker DJ, Flatt PR, Fritsche A, Gribble F, Grill HJ, Habener JF, Holst JJ, Langhans W, Meier JJ, Nauck MA, Perez-Tilve D, Pocai A, Reimann F, Sandoval DA, Schwartz TW, Seeley RJ, Stemmer K, TangChristensen M, Woods SC, DiMarchi RD, Tschop MH (2019) Glucagon-like peptide 1 (GLP-1). Mol Metab 30:72-130. https:// doi.org/10.1016/j.molmet.2019.09.010

Oride A, Kanasaki H, Mijiddorj T, Sukhbaatar U, Hara T, Tumurbaatar T, Kyo S (2017) GLP-1 increases Kiss-1 mRNA expression in kisspeptin-expressing neuronal cells. Biol Reprod 97(2):240-248. https://doi.org/10.1093/biolre/iox087

Orskov C, Poulsen SS, Moller M, Holst JJ (1996) Glucagon-like peptide I receptors in the subfornical organ and the area postrema are accessible to circulating glucagon-like peptide I. Diabetes 45(6):832-835. https://doi.org/10.2337/diab.45.6.832

Paxinos G, Watson C (2013) The rat brain in stereotaxic coordinates, 7th edn. Academic Press, San Diego

Péterfi Z, Szilvásy-Szabó A, Farkas E, Ruska Y, Pyke C, Knudsen LB, Fekete C (2020) GLP-1 regulates the POMC neurons of the arcuate nucleus both directly and indirectly via presynaptic action. Neuroendocrinology. https://doi.org/10.1159/000512806 (Online ahead of print)
Pi-Sunyer X, Astrup A, Fujioka K, Greenway F, Halpern A, Krempf M, Lau DC, le Roux CW, Ortiz RV, Jensen CB, Wilding JP (2015) A randomized, controlled trial of $3.0 \mathrm{mg}$ of liraglutide in weight management. N Engl J Med 373(1):11-22. https://doi. org/10.1056/NEJMoa1411892

Rebosio C, Balbi M, Passalacqua M, Ricciarelli R, Fedele E (2018) Presynaptic GLP-1 receptors enhance the depolarization-evoked release of glutamate and GABA in the mouse cortex and hippocampus. BioFactors (Oxford, England) 44(2):148-157. https ://doi.org/10.1002/biof.1406

Richard JE, Anderberg RH, Goteson A, Gribble FM, Reimann F, Skibicka KP (2015) Activation of the GLP-1 receptors in the nucleus of the solitary tract reduces food reward behavior and targets the mesolimbic system. PLoS ONE 10(3):e0119034. https ://doi.org/10.1371/journal.pone.0119034

Rowlands J, Heng J, Newsholme P, Carlessi R (2018) Pleiotropic effects of GLP-1 and analogs on cell signaling, metabolism, and function. Front Endocrinol (Lausanne) 9:672. https://doi. org/10.3389/fendo.2018.00672

Secher A, Jelsing J, Baquero AF, Hecksher-Sorensen J, Cowley MA, Dalboge LS, Hansen G, Grove KL, Pyke C, Raun K, Schaffer L, Tang-Christensen M, Verma S, Witgen BM, Vrang N, Bjerre Knudsen L (2014) The arcuate nucleus mediates GLP-1 receptor agonist liraglutide-dependent weight loss. J Clin Invest 124(10):4473-4488. https://doi.org/10.1172/JCI75276

Publisher's Note Springer Nature remains neutral with regard to jurisdictional claims in published maps and institutional affiliations. 